Preprints of the

Max Planck Institute for

Research on Collective Goods

Bonn 2013/19

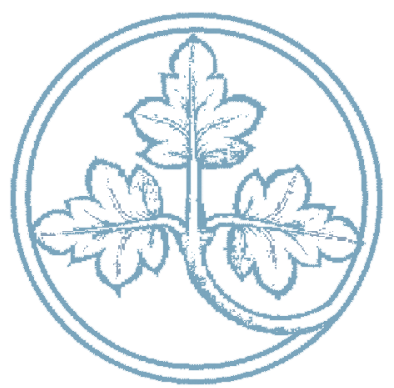

Tacit Coordination in Games with Third-Party Externalities

James Bland

Nikos Nikiforakis

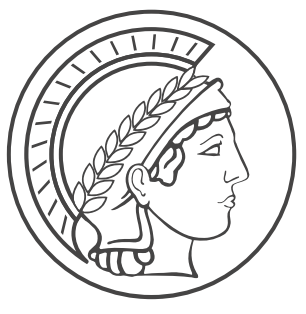




\title{
Tacit Coordination in Games with Third-Party Externalities
}

\author{
James Bland / Nikos Nikiforakis
}

October 2013 


\title{
Tacit Coordination in Games with Third-Party Externalities*
}

\author{
James Bland and Nikos Nikiforakis ${ }^{\dagger}$
}

October 1, 2013

\begin{abstract}
When agents face coordination problems their choices often impose externalities on third parties. We investigate whether such externalities can affect equilibrium selection in a series of one-shot coordination games varying the size and the sign of the externality. We find that third-party externalities have a limited effect on decisions. A large majority of participants in the experiment are willing to take an action that increases their income slightly, even if doing so causes substantial inequalities and reductions in overall efficiency. Individuals revealed to be other-regarding in a nonstrategic allocation task often behave as-if selfish when trying to coordinate.
\end{abstract}

JEL codes: C90, D01, D03, D62, D63

Keywords: tacit coordination, social preferences, externalities, equilibrium selection, efficiency.

\footnotetext{
${ }^{*}$ For helpful comments we thank Jim Andreoni, Loukas Balafoutas, Maria Bigoni, Olivier Bochet, Gary Charness, Dirk Engelmann, Tim Cason, Christoph Engel, Sven Fischer, Dominik Grafenhofer, Ben Greiner, Shachar Kariv, Rebecca Morton, Joerg Oeccshler, Jan Stoop, Lilia Zhurakhovska, seminar participants at the Max-Planck Institute for Research on Collective Goods, New York University, University of Düsseldorf, University of Heidelberg, University of Melbourne, University of Sydney and conference participants at the 2012 International and European Meetings of the Economics Science Association, 2012 MBEES in Maastricht, and 2011 Australian-New Zealand Workshop in Experimental Economics. Funding from the Faculty of Business \& Economics at the University of Melbourne is gratefully acknowledged. This project was approved by the Faculty of Business \& Economics Ethics Committee at the University of Melbourne.

${ }^{\dagger} B$ land: Department of Economics, Purdue University, Krannert Building, 425 W. State Street, West Lafayette, IN 47907; E-mail: james.bland@gmail.com. Nikiforakis (corresponding author): (i) Department of Economics, The University of Melbourne, Victoria 3010, Australia; (ii) Max Planck Institute for Research on Collective Goods, Kurt Schumacher Strasse 10, 53113 Bonn, Germany; (iii) CNRS, Groupe d'Analyse et de Théorie Economique Lyon St Etienne, 93 Chemin des Mouilles, 69130 Ecully, France; E-mail: n.nikiforakis@gmail.com.
} 


\section{Introduction}

In many instances when agents face coordination problems in daily life, the choices of the decision makers will not only affect their welfare, but also impose externalities on third parties. A classic example of such a coordination problem in economics is tacit collusion where firms try to coordinate actions to increase their profits (e.g., by simultaneously restricting output or raising prices), but in doing so they reduce the surplus of consumers. ${ }^{1}$ There are also several other examples. Macroeconomic models with trade, production and search externalities often admit multiple equilibria, with agents' choices affecting the entire economy (Cooper and John, 1988). In microeconomics, contracting externalities between employees/committee members/shareholders can lead to coordination failure and reduce the welfare of different third parties such as employers, co-workers, and the general public (e.g., Genicot and Ray, 2006; Segal, 2003).

This paper investigates whether third-party externalities can affect equilibrium selection in coordination games. We think this is an important question given that third-party externalities are common in many contexts and, economically, they can be quite significant. ${ }^{2}$ There is also another reason. Traditional economic models postulate that all individuals do not care about the welfare of others and that these preferences are common knowledge. Under these assumptions, decision makers will ignore the consequences their actions have on non-decision makers when facing coordination problems; a fact which may explain why researchers have so far focused exclusively on the decision makers' private incentives overlooking the potential role of third-party externalities. However, by now there is considerable evidence from bargaining and social-dilemma experiments challenging the parsimony of these assumptions, suggesting that at least some individuals are not entirely selfish but have social preferences, i.e., their utility does not depend only on their material payoff, but also on that of other decision makers (e.g., Andreoni et al. 2003; Engelmann and Strobel, 2004; Fisman et al., 2007) and, sometimes, on that of third parties (e.g., Ellman and Pezanis-Christou, 2010; McDonald et al., 2013).

While this evidence suggests that third-party externalities can affect tacit coordination,

\footnotetext{
${ }^{1}$ For recent empirical evidence see Sweeting (2009) who finds that U.S. radio stations try to coordinate the time at which commercials are aired in an attempt to prevent listeners from switching stations. Note that collusion can be sustained in equilibrium if firms interact for an indefinitely long time horizon. Of course, this is not the only equilibrium of the game.

${ }^{2}$ Trade or other form of externalities can be so severe that they create a need for policy coordination (e.g., Canzoneri et al., 2005). In fact, many observers argued that the recent euro debt crisis which affected individuals around the world was partly caused by the inability of national governments to coordinate fiscal policies (e.g., Vits and Thesing, 2011). As another example, consider the coordination problem involved in developing cars using environment-friendly fuel. Car producers, fuel providers and perspective car buyers all need to coordinate their actions so that the new vehicles can be produced. The production of such cars has large, long-lasting externalities on the environment and even non-drivers (Farrell and Sperling, 2007).
} 
it remains an open question to what extent this happens in practice. To see why, consider the $2 \times 2$ coordination game in Table 1 . Two players, $\mathrm{X}$ and $\mathrm{Y}$, must choose simultaneously between actions $H$ and $L$. If both take action $L$, then each receives 5 ECU, while a third party, Z, earns 4 units. If both choose $H$, each receives 7 units, while $\mathrm{Z}$ earns $z_{H}$ units. If $\mathrm{X}$ and Y choose different actions, all earn 0 units. ${ }^{3}$ Assume for a moment that $z_{H}=-4$. What should $\mathrm{X}$ choose? On the one hand, if they coordinate with player $\mathrm{Y}$ on $H$ she earns more. On the other hand, doing so hurts the third party. Even if $\mathrm{X}$ cares sufficiently about the welfare of $\mathrm{Z}$ so that she prefers outcome $(L, L)$ to $(H, H)$, she may still choose strategy $H$ if she believes that $\mathrm{Y}$ will choose $H$. In contrast, even if $\mathrm{X}$ does not care about the welfare of $\mathrm{Z}$, she may choose strategy $L$ if she believes that $\mathrm{Y}$ will also do the same.

The example above illustrates that the uncertainty about others' social concerns may amplify or weaken individuals' willingness to act selfishly when trying to coordinate on an action. Ultimately, whether or not third-party externalities affect equilibrium selection will depend partly on the decision-makers' social preferences, and partly on their beliefs about the likelihood that other decision makers will act on the interest of third parties. If individuals believe that other decision makers are likely to act on it, then even selfish decision makers may decide to do the same and behave as-if other-regarding. If they believe other decision makers are unlikely to act on it, then even other-regarding individuals may choose to behave as-if selfish when facing a coordination problem. This is why it is difficult to predict the impact third-party externalities will have in coordination games.

This paper presents evidence from two laboratory experiments investigating how thirdparty externalities affect tacit coordination. Controled experiments have been used repeatedly to study games with multiple equilibria. To focus on the impact of third-party externalities on coordination, we study two classes of simple coordination games in which the decision-makers' incentives are alligned and no inequality exists in their payoffs in either of the two pure-strategy equilibria (as in Table 1). If the third-party externality is ignored, the coordination problem is trivial as the two pure-strategy equilibria are Pareto ranked and payoff dominance is the only plausible criterion for equilibrium selection. In other words, strategic uncertainty in our experiment arises primarily from the uncertainty regarding how much the other decision maker cares about the welfare of the third party.

In total, we examine behavior in 18 coordination games varying the sign and the size of the externality. To guide our analysis, we derive behavioral hypotheses using two models of social preferences. The first assumes that individuals dislike inequality in payoffs, while the second assumes that they exhibit efficiency (and maximin) concerns. ${ }^{4}$ The two experiments

\footnotetext{
${ }^{3}$ In this example, for simplicity, we assume that social preferences are not so strong that X prefers coordination failure to coordination at $(H, H)$. We discuss this issue in more detail later in the paper.

${ }^{4}$ Following Charness and Rabin (2002), in this paper we define efficiency as a preference for increasing
} 
help us evaluate the predictive power of these models. Further, to assess the role of social preferences, we elicit participants' distributional preferences using a simple allocation task in both experiment, and use them to understand behavior in the coordination games.

Our findings indicate that third-party externalities do have an effect on choices in the coordination game, but this is rather limited. By and large, concerns for one's own earnings easily dominate other social concerns. More than $70 \%$ of the participants are revealed to prefer a small increase in their own material payoff, even if this would $(i)$ impose a negative externality ten times as large on an inactive participant, $(i i)$ increase inequality in payoffs and (iii) reduce efficiency. Most individuals appear to expect this. In the coordination game, decision makers exhibiting social preferences choose the action that imposes the negative externality more often than not. In sharp contrast, participants with a stronger preference for own-payoff maximization almost never chose the action that avoids the externality in the coordination game. That is, the strategic uncertainty in the coordination game appears to make subjects behave more selfishly rather than more pro-socially.

Amongst participants revealed to have social preferences, we find that efficiency concerns are more important than those for equality, which appear to play little role in our experiment. In particular, individuals are not willing to incur a small payoff reduction to avoid large positive externalities that would increase inequality in favor of the third party. Therefore, our data is not well explained by the model of Fehr and Schmidt (1999) which predicts that decision makers will be on average more likely to avoid large positive externalities, than negative externalities of an equal magnitude. The model of Charness-Rabin (2002) in which some individuals are assumed to care about efficiency and the lowest payoff in the group, does a good job at organizing the aggregate patterns in our data. In particular, this model can account for our finding that subjects are more likely to incur a cost to avoid reducing efficiency than they are to increase it.

The paper proceeds as follows. In the next section, we present a literature review of related studies. In section 3, we discuss the design and results of the first experiment. In section 4, we do the same for Experiment 2. Section 5 discusses a mixture model estimating the different behavioral types in our experiment, while section 6 concludes with a summary of our findings, and a discussion of their implications for equilibrium selection and topics for future research.

the aggregate payoff of group members. This definition of efficiency may seem odd to some when the game does not allow for monetary transfers across players. Nevertheless, many experimental subjects appear to care for the sum of group earnings (e.g., Engelmann and Strobel, 2004). 


\section{Related literature}

This is the first study to explore how third-party externalities affect equilibrium selection. In doing this, it contributes to two different strands of literature. The first strand explores the existence and nature of social preferences. This literature is vast and well surveyed elsewhere (e.g., Cooper and Kagel, 2013). Most studies focus their attention on social concerns regarding the welfare of other decision makers (i.e., second parties) and document the willingness of a substantial fraction of participants to help (or hurt) them at a personal cost. In many economic contexts, however, decision makers impose externalities also on third parties (e.g., environmental pollution, tacit collusion).

A small number of studies have investigated how the presence of third parties (i.e., non-decision makers) affects behavior in bargaining and social dilemma experiments. The evidence suggests that participants care less about the welfare of inactive third parties than the welfare of other decision makers (e.g., Engel and Zhurakhovska, 2012; Güth and van Damme, 1998; Kagel and Wolfe, 2001). Nevertheless, the existence of third parties has been shown to have a significant impact on behavior (e.g., Ellman and Pezanis-Christou, 201), especially when decision makers are in a worse monetary position than the third parties (Engel and Rockenbach, 2011; McDonald et al., 2013). ${ }^{5}$ Furthermore, even if agents care less about third parties, the uncertainty about the social preferences of other decision makers in our experiment could serve as a multiplier increasing the number of agents willing to act in the interest of the third party.

The second literature our study contributes to is that on tacit coordination. There is a long history of using controlled experiments to investigate equilibrium selection in coordination games (see Camerer, 2003). Despite this and the large literature on social preferences, there is only one study on how social concerns affect equilibrium selection. Chmura et al. (2005) examine how concerns for efficiency and equality in the payoffs of decision makers affect choices in $2 \times 2$ coordination games. Unlike in our experiment, actions do not impose externalities on third parties. Chmura et al. (2005) find that concerns for equality and efficiency are both important determinants of decisions in their coordination game.

The two studies which are most closely related to ours are Bigoni et al. (2013) and Cason and Mui (2007). They investigate behavior in two different three-player, two-stage games. In both cases, a $2 \times 2$ coordination game is (sometimes) embedded in the second stage of the game. In these instances, the choices of the two decision makers determine the payoffs

\footnotetext{
${ }^{5}$ Engel and Rockenbach (2011) examine how third-party externalities affect contributions in a publicgood game. The game is finitely repeated and thus has a unique equilibrium under plausible behavioral assumptions (see e.g., Fehr and Schmidt, 1999). McDonald et al. (2013) investigate how the (exogenously determined) payoff of a third party in an ultimatum game affects bargaining.
} 
for all three players. An important difference to our experiment is that the "third" player is not inactive in these studies. In particular, they make a decision in the first stage of the game which determines the options/payoffs available to players in the second stage. Thus, although these studies are related, their focus is not on the impact of third-party externalities per se. In addition, unlike these authors, we vary systematically the size, sign and impact of the externality to better understand when such externalities may matter.

\section{Experiment 1}

The experiment consists of two parts. In the first part, participants play a series of coordination games. In the second part, they complete an allocation task. These tasks are described in detail below.

\subsection{The coordination game}

The basic coordination game used in Experiment 1 is presented in Table 1. As mentioned, Players $\mathrm{X}$ and $\mathrm{Y}$ must choose simultaneously between two actions: $H$ and $L$. If both take action $H$, then players $\mathrm{X}$ and $\mathrm{Y}$ earn 7 ECU each, while an inactive third party (Person Z) earns $z_{H}$ ECU - our treatment variable. If players $\mathrm{X}$ and $\mathrm{Y}$ instead take action $L$, then they each receive $5 \mathrm{ECU}$, while $\mathrm{Z}$ earns 4 ECU. ${ }^{6}$ If players $\mathrm{X}$ and $\mathrm{Y}$ fail to coordinate and choose different actions, all participants earn 0 ECU. All payoffs in ECUs are common knowledge. Henceforth, when we mention third-party externality, E, we refer to the difference in Z's payoff in $(H, H)$ and $(L, L)$, that is, $E=z_{H}-4$. While one can think of other definitions for the externality, we favor this one for reasons that will become apparent when we discuss the different behavioral models.

If it is common knowledge that players $\mathrm{X}$ and $\mathrm{Y}$ do not care about $z_{H}$, then the decisionmakers' task would be relatively simple. The game has two pure-strategy Nash equilibria, $(H, H)$ and $(L, L)$, which are Pareto ranked. Since $(H, H)$ is payoff dominant and there are no other candidates for a coordination device, it seems likely that this equilibrium would be selected. ${ }^{7}$ However, even if $X$ and $Y$ do not care about $z$, they may still be concerned that the other party does. Therefore, the presence of third-party externalities amplifies the strategic

\footnotetext{
${ }^{6}$ We purposefully chose the payoff to Person $\mathrm{Z}$ such that earnings in combination $(L, L)$ are similar, but not exactly the same. We did this to distinguish between concerns for equality and the symmetry of an outcome. Symmetry may act as a coordination device, and lead to players choosing $L$ not because they care about the equality per se, but because $(L, L)$ is more focal due to the symmetry (Crawford et al., 2008; Mehta, 1994).

${ }^{7}$ This is the reason we chose to have decision makers earn 0 ECU in case of coordination failure rather than a positive amount as, e.g., in the stag-hunt game, as this could create a tension between payoff-dominance and risk-dominance.
} 
uncertainty faced by decision makers; for some values of $z_{H}$, Player X may prefer $(L, L)$ to $(H, H)$, but Player Y cannot be sure about this. The fact that the difference between the decision-makers' earnings at $(L, L)$ and $(H, H)$ is relatively small is also expected to increase the likelihood that, for some extreme values of $z_{H}$, decision makers will try to coordinate at $(L, L)$ as they do not have to care especially strongly for the third party to prefer $(L, L)$, and even selfish decision makers do not need to be especially certain about their opponent taking action $L$ for themselves to do so as well.

Models in which individuals are assumed to have concerns for equality in payoffs suggest that individuals may be averse to both positive and negative externalities (e.g., Bolton and Ockenfels, 2000; Fehr and Schmidt, 1999). Motivated by these models we study behavior for 9 different values of $z_{H}$. In particular, $z_{H}=\{-16,-12,-8,-4,0,4,8,12,16\}$, which translates into a third-party externality $E=\{-20,-16,-12,-8,-4,0,4,8,12\}$. As a benchmark for comparison, we will consider the case when $z_{H}=4$ and thus $E=0$. The rationale for this choice as well as for studying this set of values which includes some very large negative and positive externalities (particularly given the small difference in the payoffs in $(L, L)$ and $(H, H)$ for the decision makers), is explained below when we present our theoretical framework.

Since we wish to examine to what extent behavior is consistent with social preferences, we opted for a within-subject design which allows us to check the internal consistency of subjects' actions. To minimize the risk of contagion effects across games, subjects did not know the 9 games they would play and also feedback was withheld until the end of the experiment. Therefore, subjects could not learn from past actions. In addition, we used 6 different random orders in which the 9 values of $z_{H}$ were presented and changed the position of actions $L$ and $H$ in Table 1 so that the outcomes with positive payoffs were sometimes on, and sometimes off the diagonal. ${ }^{8}$ This was done to ensure that subjects could not easily identify that the variable of interest was $z_{H}$. The fact subjects did not know what the 9 games would be, the different values of $z_{H}$ or even that $z_{H}$ would be the only parameter changing, implies that, especially for the first few treatments in a sequence, it was not obvious that the decision makers could possibly smooth out Person Z's earnings throughout the sequence by always choosing $H$. In the results section we provide evidence showing that behavior was similar in treatments irrespective of whether they were played early in the sequence or later. This indicates that subjects treated each game independently and that there were no contagion effects.

Participants were paid for each of the nine decisions in this part of the experiment. This

\footnotetext{
${ }^{8}$ In the experiment, actions were labelled as $x 1$ and $x 2$ for Player $\mathrm{X}$, and $y 1$ and $y 2$ for Y. The instructions explained to subjects how to read a payoff table and that there would be two decision makers and an inactive person, but not that the decision-makers' payoffs would be held constant or that they would be equal.
} 
was done for three reasons. First, it encourages subjects to think carefully about each of the nine decisions. Second, it reduces considerably the probability that Person $\mathrm{Z}$ will walk away with negative earnings from the experiment (indeed, none of the participants had negative earnings at the end of the experiment). All participants were supplied with the same information regarding the experiment, irrespective of their role. In particular, it was public information that Person $\mathrm{Z}$ was aware of the task the other group members would be performing in part 1, the actions available to them, and that they would be informed of their group-members' actions at the end of the experiment, but not before. Providing this information to Person $\mathrm{Z}$ was meant to increase the likelihood that third-party externalities would affect coordination.

\subsection{The allocation task}

While the actions in the coordination game are sufficient to address our research question whether third-party externalities affect equilibrium selection, we would also like to be able to say something about the driving forces of these actions. Observing an individual taking action $L$ in the coordination game does not inform us on its own of their preferences or beliefs. In order to separate these aspects of the decision-making process, participants' preferences are elicited in an allocation task seen in Table 2. In this task, players X and Y were asked to choose between allocations $h$ and $l$. Since actions lead directly to earnings in this task, players do not need to form beliefs about the actions of others when making these decisions. Payoffs in this task are identical to the "equilibrium" payoffs in the coordination game, so choosing allocation $h$ in the allocation task for a particular $z_{H}$ suggests that this individual (weakly) prefers outcome $(H, H)$ in the coordination game with the same $z_{H}$. Similarly, if an individual selects allocation $l$ suggests that they (weakly) prefer outcome $(L, L)$.

Participants performed the allocation task for the same nine values of $z_{H}$ presented above. One allocation of each of players $\mathrm{X}$ and $\mathrm{Y}$ (i.e., two per group) was randomly chosen and added to participants' final earnings. In order to control for any order effects, half of the subjects in each session were presented the allocation task with $z_{H}$ in ascending order, and the other in decreasing order. However, as we will see below, we do not find any such order effects.

While it would be useful to have an accurate measure of participants' beliefs in the coordination game, it is known that such procedures can have undesired effects, e.g., by introducing hedging opportunities or altering the way in which subject think about their tasks (Blanco et al., 2010). ${ }^{9}$ We could of course have avoided hedging opportunities by paying

\footnotetext{
${ }^{9}$ In their influential study on coordination games, van Huyck et al., (1990) find that 90 percent of subjects report non-equilibrium beliefs. The reported beliefs are however consistent with hedging.
} 
either the coordination or the allocation task. However, since we are primarily interested in the effect of externalities on the actions in the coordination game, we decided not to weaken monetary incentives and ultimately not to elicit beliefs. For the same reason, participants always completed the allocation task in the second part of the experiment. Completing it in the first part would increase the salience of third-party externalities and thus could affect tacit coordination in an undesired way.

\subsection{Theoretical framework \& behavioral hypotheses}

As mentioned, if it is common knowledge that players $\mathrm{X}$ and $\mathrm{Y}$ do not care about the third-party externality, then the game in Table 1 has two pure-strategy, Pareto-ranked Nash equilibria for all $z_{H},(H, H)$ and $(L, L)$. Since $(H, H)$ is payoff dominant we would expect most decision makers to choose $H$. However, this (joint) assumption is unlikely to hold in practice, especially given that we consider one-shot coordination games and the evidence discussed in the introduction that some participants are motivated by concerns for efficiency and equality.

In order to obtain an intuition as to how such concerns could affect behavior in our experiment, in this section, we utilize two widely-used models of social preferences. The first is the model of inequality aversion by Fehr and Schmidt (1999; FS). The second is the model of Charness and Rabin (2002; CR) which assumes that individuals care for efficiency and the minimum payoff in their group. Both models assume that an individual $i$ strictly prefers more of their own earnings $\left(x_{i}\right)$ to less and that their utility depends in varying degrees on the earnings of others $\left(x_{j \neq i}\right)$. Both models also allow for complete selfishness by setting the parameters to zero in which case $u_{i}(x)=x_{i}$.

The FS model is presented in equation 1. An individual $i$ is assumed to strictly prefer more of their own earnings $\left(x_{i}\right)$ to less, while their utility is assumed also to depend on the earnings of the other $n-1$ individuals in his reference group $\left(x_{j \neq i}\right)$. An FS-individual

prefers, all else equal, for others to receive the same earnings as themselves, suffering from "envy" (captured by $\alpha_{i} \geq 0$ ) or "guilt" (captured by $\beta_{i} \geq 0$ ) when others' earnings differ from their own. This model further assumes that envy is at least as strong as guilt $\left(\alpha_{i} \geq \beta_{i}\right)$, and that guilt cannot be so strong that the individual would be willing to throw away their own money in order to improve equality $\left(\beta_{i}<1\right)$.

$$
\begin{aligned}
u_{i}(\mathbf{x}) & =x_{i}-\frac{\alpha_{i}}{n-1} \sum_{j \neq i} \max \left\{x_{j}-x_{i}, 0\right\}-\frac{\beta_{i}}{n-1} \sum_{j \neq i} \max \left\{x_{i}-x_{j}, 0\right\} \\
0 & \leq \beta_{i}<1, \quad \alpha_{i} \geq \beta_{i}
\end{aligned}
$$


Charness and Rabin (2002, p. 852) assume that the utility of individual $i$ is given by

$$
u_{i}(\mathbf{x})=\left(1-\lambda_{i}\right) x_{i}+\lambda_{i}\left[\delta_{i} \min \{\mathbf{x}\}+\left(1-\delta_{i}\right) \sum_{j=1}^{n} x_{j}\right], \quad\left(\lambda_{i}, \delta_{i}\right) \in[0,1]^{2}
$$

where $\mathbf{x}$ is a vector including the earnings of each group member. In this model, individual $i$ cares for her own material payoff, but places a weight $\lambda_{i}$ on other (social) considerations. These considerations include the sum of group earnings (weighted by $1-\delta_{i}$ ) and the minimum earnings of a group member (weighted by $\delta_{i}$ ). To simplify the comparison to the selfish and FS models, throughout the paper we assume that $\lambda \neq 1$ (i.e., $i$ does care for his income) which allows us to rewrite the model as

$$
u_{i}(\mathbf{x})=x_{i}+\gamma_{i} \min \{\mathbf{x}\}+\rho_{i} \sum_{j=1}^{n} x_{j}, \quad \gamma_{i}, \rho_{i} \geq 0
$$

where, $\gamma_{i}=\frac{\lambda_{i} \delta_{i}}{1-\lambda_{i}}, \quad \rho_{i}=\frac{\lambda_{i}\left(1-\delta_{i}\right)}{1-\lambda_{i}}$. Since maximin and efficiency concerns have almost identical implications given our parameters in Experiment 1, we further simplify the discussion by assuming $\delta_{i}=0$, which implies $\gamma_{i}=0$. Later in the paper, we discuss the full model of Charness and Rabin (2002) allowing for maximin preferences. We also present evidence from a mixture model that allows us to estimate the relative importance of efficiency and maximin concerns, which justifies our decision to focus on efficiency rather than maximin preferences at this point in our paper. A CR-individual prefers higher group earnings to lower group earnings, which is captured by the parameter $\rho_{i} \geq 0$.

$$
\begin{aligned}
u_{i}(\mathbf{x}) & =x_{i}+\rho_{i} \sum_{j=1}^{n} x_{j} \\
\rho_{i} & \geq 0
\end{aligned}
$$

We first introduce the models in the context of the allocation task, and then discuss the role these preferences play in the coordination game.

\subsubsection{Decisions in the allocation task}

The allocation task allows us to determine how changes in $z_{H}$ in Table 2 affect a decision maker's ranking of the $(H, H)$ and $(L, L)$ outcomes in Table 1. An individual will choose allocation $l$ if and only if $u_{i}(5,5,4) \geq u_{i}\left(7,7, z_{H}\right)$ (note that, for convenience, we assume that indifferent individuals prefer $l$ over $h$ ). For FS-individuals, this occurs when $z_{H} \leq 6-\frac{4}{\beta_{i}}$ or $z_{H} \geq \frac{4+\beta_{i}}{\alpha_{i}}+7$, while for CR-individuals when $z_{H} \leq-\frac{2}{\rho_{i}}$. Given the parameter restrictions, 
if individuals are FS (CR), we would only observe them taking action $l$ if:

$$
\begin{array}{ll}
\mathrm{FS}: z_{H}<2 & \text { or } \quad z_{H}>7 \\
\mathrm{CR}: z_{H}<0 &
\end{array}
$$

These conditions allow us to make a number of useful observations. First, given that $x_{i}$ is higher in allocation $h$ than $l$, an efficiency-minded, CR-individual will only prefer outcome $l$ when the total group earnings are below those in allocation $h$ (i.e., $\sum x_{j}<14$ ), which occurs when $z_{H}<0$. As $z_{H}$ decreases further, assuming a non-degenerate distribution of $\rho_{i}$, condition (5) will be satisfied for an increasing number of efficiency-minded people who will choose $l$ over $h$. Second, efficiency-minded people do not mind positive externalities (in fact, they derive utility from them) and hence prefer $h$ over $l$ when $z_{H} \geq 0$. This is not the case for inequality-averse individuals as condition (4) illustrates. Strongly envious FS-individuals may prefer $l$ to $h$ when $z_{H}>7$. Third, since $\beta_{i}<1$, the most inequality-averse individual would prefer $h$ over $l$ until $z_{H}$ is below 2. At this point, the most guilt-prone FS-individuals will prefer $l$ over $h$. Fourth, the $\alpha_{i} \geq \beta_{i}$ restriction in the FS model implies that individuals care at least as strongly for positive as for negative externalities. Finally, the last observation we wish to make is that selfish, inequality averse and efficiency-minded individuals alike all prefer $h$ to $l$ when $z_{H} \in[2,7]$. In our expreriment there is only one value of $z_{H}$ in this range $\left(z_{H}=4\right)$. Therefore, we have good reasons to believe that when $z_{H}=4$ individuals will face the least strategic uncertainty. We will consider $z_{H}=4$ to be our baseline treatment.

Hypothesis 1 (Baseline treatment): The lowest degree of strategic uncertainty will be when $z_{H}=4$, i.e., when there are no third-party externalities $(E=0)$.

\subsubsection{Decisions in the coordination game}

Turning to the game in Table 1, the first thing to consider is that, with the addition of Person Z, the game may no longer be a coordination game for some individuals who have social preferences. In particular, while selfish, FS- and CR-individuals will always prefer the $(L, L)$ outcome to coordination failure, i.e., the $(0,0,0)$ set of payoffs, individuals that strongly dislike inequalities or inefficiencies may prefer coordination failure to the $(H, H)$ outcome for sufficiently large externalities. For these decision makers $L$ will be a dominant strategy. This will occur for FS-individuals if and only if $z_{H} \leq 7-\frac{14}{\beta_{i}}$ or $z_{H} \geq \frac{14}{\alpha_{i}}+7$, and for CR-individuals if and only if $z_{H} \leq \frac{-7}{\rho_{i}}-14$. Given the parameter restrictions, $L$ will be 
a dominant strategy for the most other-regarding FS (CR) individuals if:

$$
\begin{aligned}
& \mathrm{FS}: z_{H}<-7 \text { or } z_{H}>7 \\
& \mathrm{CR}: z_{H}<-14
\end{aligned}
$$

Given the values of $z_{H}$ used in the experiment, clearly the condition is more likely to be satisfied for inequality-averse rather than efficiency-minded decision makers. However, we note that given the estimates of $\alpha_{i}$ and $\beta_{i}$ in Blanco et al. (2011) and the values for $z_{H}$ in our experiment, it seems unlikely that these condition will be met for most FS-individuals. ${ }^{10}$

For the remaining decision makers, the game in Table 1 poses a coordination problem. How should they choose? Suppose that individual $i$ has subjective beliefs $p_{i} \in[0,1]$ that their opponent will choose action $L .^{11}$ Assuming that $i$ is an expected-utility maximizer, they will play $L$ if and only if (normalizing $\left.u_{i}(0,0,0)=0\right)$ :

$$
p_{i} u_{i}(5,5,4) \geq\left(1-p_{i}\right) u_{i}\left(7,7, z_{H}\right) \Longleftrightarrow p_{i} \geq \frac{u_{i}\left(7,7, z_{H}\right)}{u_{i}(5,5,4)+u_{i}\left(7,7, z_{H}\right)}
$$

Condition (8) allows some first observations regarding behavior in the coordination game. When $p_{i}=\frac{1}{2}$, it implies that if individual $i$ chooses $h(l)$ in the allocation task for a given $z_{H}$ then they will choose $H(L)$ in the coordination game for the same $z_{H}$. If $p_{i}>\frac{1}{2}$, then depending on the strength of their preferences, some individuals preferring $h$ to $l$ may take action $L$ in the coordination game. Similarly, if $p_{i}<\frac{1}{2}$, depending on the strength of their preferences, some individuals choosing $l$ in the allocation task may take action $H$ in the coordination game that do not correspond to the outcome that is revealed preferred (provided that $L$ is not a dominant strategy). In other words, if we observe individuals making these kinds of "switches" we can infer something about their subjective beliefs.

In general, if $p_{i}=c \in(0,1)$, i.e., if subjective beliefs are not a function of $z_{H}$, then we would expect to observe the same qualitative change in choices of $L$ as in the allocation task. ${ }^{12}$ This motivates the following hypotheses regarding behavior in the coordination game:

\footnotetext{
${ }^{10}$ For example, Blanco et al. (2011) estimate that the highest value of $\beta_{i}$ is 0.5 . This would imply that $z_{H} \leq-21$ for $L$ to be a dominant strategy. Similarly, the highest estimate of $\alpha_{i}$ is 4.5 (while most subjects in their experiment have a much lower $\alpha_{i}$ ) which implies that $z_{H}>10$ for the most envious subjects to have $L$ as a dominant strategy. .

${ }^{11}$ We have also calculated a Bayes Nash Equilibrium, but chose not to present it here as the assumption that players have a common prior regarding the distribution of players' types is highly unrealistic in oneshot games. The comparative statics we obtain, however, from the BNE are similar to those we obtain if we assume that participants have subjective beliefs.

${ }^{12}$ Of course, it is possible that $p_{i}$ is not constant but that it increases with the absolute value of $z_{H}$. One explanation for this is that as the externality increases, the fraction of players with $L$ as a dominant strategy can only increase. Beliefs about the distribution of preferences therefore place a lower bound on subjective beliefs about actions. If $p_{i}$ increases as the externality becomes larger in absolute terms, the effects discussed below in our hypotheses should be stronger than if $p_{i}$ is constant for all $z_{H}$.
} 
Hypothesis 2 (Negative Externalities): If participants have FS (or CR) preferences, then compared to the baseline treatment of $z_{H}=4$ and $E=0$, participants will be more likely to take action $L$ to avoid negative third-party externalities, i.e., when $z_{H}<4$. The proportion of individuals taking action $L$ will increase as $z_{H}$ decreases further.

Hypothesis 3 (Positive Externalities): If participants have FS preferences, then compared to the baseline treatment of $z_{H}=4$ and $E=0$, participants will be more likely to take action $L$ to avoid positive third-party externalities, i.e., when $z_{H}>7$. The proportion of FS-individuals taking action $L$ will increase as $z_{H}$ increases further.

Note that Hypothesis 3 only discusses inequality-averse individuals. If participants have CR-preferences, then positive externalities will not increase the proportion of $L$ actions beyond $z_{H}=4$. Therefore, in Experiment 1, efficiency-minded individuals will behave like selfish subjects with regards to positive externalities.

\subsection{Procedures}

The first experiment was conducted at the Experimental Economics Laboratory at the University of Melbourne in March and April of 2011 using z-Tree (Fischbacher, 2007). The 105 participants (70 decision-makers) were students of the University of Melbourne, randomly selected from a database of more than 3,000 people using ORSEE (Greiner, 2004) after excluding students with economics or psychology majors. As the exchange rate between Experimental Currency Units (ECU) and the Australian Dollar was 1ECU $=\mathrm{AU} \$ 0.50$, the stakes were substantial both for decision makers as well as for third parties that could lose e.g., $\$ 8$ when $z_{H}=-16$. Each individual participated in one of six sessions lasting approximately one hour and earned $\$ 33.36$ on average, including a $\$ 10.00$ endowment, in Australian Dollars. Players $\mathrm{X}$ and $\mathrm{Y}$ earned $\$ 41.81$ on average. At the time of the experiment, 1 Australian Dollar $=1.07$ U.S. Dollars; the minimum hourly wage in Australia was $\$ 15.00$.

All participants were given instructions describing the task they and their group members would be performing in the coordination game, as well as an assurance that they could leave with their earnings at the end of the experiment without their identity being revealed. Roles were randomly allocated and remained fixed throughout the experiment. Before the start of the experiment, participants assigned the roles of players $\mathrm{X}$ and $\mathrm{Y}$ answered some control questions to establish that they understood the task they were performing, how others' actions affected their earnings, and when they would receive feedback. When all control questions had been answered correctly, an experimenter announced that all control questions had been answered correctly and read aloud a summary of the instructions for Part 1 to ensure that they were common knowledge. Participants were aware that there 
would be a second part to the experiment, but did not know what the content of that part would be. Once the first part was completed, a similar procedure for instructions, control questions, and summary was used in the second part. At the end of the experiment, all participants (including Person Z) were shown feedback screens displaying their earnings and their group's actions that were selected for payment. Player Z, as promised in the instructions, was additionally shown all the actions taken by Players $\mathrm{X}$ and $\mathrm{Y}$ that were not selected for payment.

\subsection{Results}

Result 1: Negative third-party externalities, affect choices in the coordination game, but not positive. Their effect, however, is limited as most subjects choose the action that maximizes their own payoff without regard for the third-party externality.

SUPPORT: The black columns in Figure 1 present the fraction of decision makers selecting $L$ in the coordination game as a function of the third-party externality $\left(E=z_{H}-4\right)$. In line with Hypothesis 1, when $E=0$, almost all individuals choose $H$. In line with Hypothesis 2 , as the negative externality increases more people choose $L$. However, the data does not seem to support Hypothesis 3 as the probability of choosing $L$ does not increase with the size of the positive externality. This is similar for the allocation task (white columns in Figure 1). This evidence therefore is not line with the Fehr and Schmidt (1999) model of inequality aversion. ${ }^{13}$ In contrast, these observations combined suggest that efficiency concerns are more important than those for equality. However, Figure 1 also reveals that the impact of third-party externalities is rather limited. Even when the externality is ten times as large $(E=-20)$ as the sacrifice required for a decision maker $(2=7-5)$ only $28 \%$ of participants choose $L$ while $72 \%$ choose $H$. Statistical support for Result 1 can be found in Table 3, which presents the results of logit regressions of actions in the coordination game against the third-party externality, controlling for individual-level random effects. As can be seen, negative externalities increase significantly the probability an individual goes against his monetary incentive and chooses $L$, but not positive externalities. A similar regression with dummy variables allowing pair-wise comparisons of behavior at different levels of $E$ with $E=0$ supports this conclusion. The table also provides evidence that there were no contagion effects in our experiment by showing that we obtain very similar results if we use observations from the first three decisions of a given session.

\footnotetext{
${ }^{13}$ We note that the data also seems to be at odds with the assumption in the FS-model that $\alpha_{i} \geq \beta_{i}$ (i.e., envy is at least as strong as guilt). Intuitively, this assumption would imply a stronger dislike for generating positive than negative third-party externalities.
} 
Result 2: Negative third-party externalities increase the rate of coordination failure and reduce efficiency. Positive externalities have no significant effect.

SUPPORT: The probability of coordination is shown in Figure 2. The figure shows that as negative externalities increase, the probability of coordination failure increases. When $E=-20$, the probability of coordination is nearly 40 percentage points smaller than when $E=0$. This is the result of the relatively small, but increasing fraction of participants choosing $L$ for a given negative externality. ${ }^{14}$ This implies that negative externalities in our experiment harm not only the third party, but also the decision makers who are more likely to fail to coordinate. As a result, players $\mathrm{X}$ and $\mathrm{Y}$ are earning on average less than $71 \%=\frac{5}{7}$ of their maximum possible when $E<0$. In expected terms, decision makers would have been better off if they had coordinated at $(L, L)$. Positive externalities do not appear to affect coordination rates relative to the treatment without externalities. Table 4 presents the results from a regression analysis. The dependent variable is the earnings of either $\mathrm{X}$ and $Y$ (regressions 1-3), or the entire group (regressions 4-6). As can be seen, larger negative externalities reduce significantly the earnings not only of $\mathrm{Z}$, but also of $\mathrm{X}$ and $\mathrm{Y}$ due to the increasing rate of coordination failure. Non-parametric tests (not reported here) lead to the same conclusions.

Result 3: Almost all participants choosing allocation $h$ chose action $H$ in the coordination game. Most of the participants who chose allocation l, chose action $H$ in the coordination game.

SUPPORT: Figure 3 presents graphically the probability an individual choosing $l(h)$ in the allocation task will choose $H(L)$ in the coordination game, as a function of the externality. It can be seen clearly that individuals choosing $l$ in the allocation task are much more likely to choose $H$ in the coordination game, than individuals choosing $h$ are to choose $L$. To obtain statistical support, since each individual makes a decision in all treatments, we use a twotailed Fisher-exact test for each value of the negative externality to compare the likelihood an individual choosing $l(h)$ will "switch" in the coordination game, i.e., they will prefer $H$ $(L)$ (there are are two few observations of people choosing $l$ when $E>0$ ). For the largest externality $(E=-20)$, of the 50 individuals who selected $h, 40(80 \%)$ individuals chose $H$ in the corresponding coordination game. In sharp contrast, only 10 of 20 individuals (50\%) choosing $l$ in the allocation task decided to take action $L$ in the coordination game. The difference is statistically significant $(p$-value $=0.019)$. The difference is also significant for each other $E \in\{-16,-12,-8\}$ ( $p$-value $<0.005)$.

\footnotetext{
${ }^{14}$ Let $q_{E}$ denote the proportion of individuals choosing $L$ for a given externality $E$, i.e., $q_{E}=\operatorname{Pr}[L \mid E]$. The probability of coordination failure is given by $1-q_{E}^{2}-\left(1-q_{E}\right)^{2}$. This expression is maximized when $q_{E}=\frac{1}{2}$.
} 


\subsection{Discussion}

The first conclusion from the experiment is that third-party externalities play only a small role in determining equilibrium selection, even when substantial. A large majority of subjects is revealed to prefer a small increase in their own material payoff and expect that other decision makers will ignore third-party externalities, even if this would entail a large negative externality on an inactive participant. As a result, decision makers with a preference for avoiding the externality often choose the action that imposes the externality in the coordination game. Hardly any participants with a preference for own-payoff maximization chose the action that avoids the externality in the coordination game.

A second insight is that concerns for equality in payoffs appear to have little (if any) influence on choices. Virtually all subjects appeared unwilling to take an action that would prevent a large positive externality making the third party considerably better off, even when the cost of doing so would be relatively small. Our data, therefore, is not well explained by the Fehr and Schmidt (1999) model of inequality aversion which predicts a stronger aversion to positive than negative externalities. A simplified version of the model by Charness and Rabin (2002) which assumes that some individuals are concerned about efficiency yields predictions which are in line with the aggregate response to positive and negative externalities.

Result 3 provides an interesting insight into decision making in the coordination game and, in particular, into the beliefs of decision makers. As mentioned, if all decision makers believe that their opponent is more likely to choose $H$, then players who prefer $h$ should choose $H$, but some who prefer $l$ may choose $H$ too. Result 3 therefore suggests that decision makers may have correctly anticipated that, as seen in Result 1 and Figure 1, most decision makers prefer $h$ to $l$. In light of this, one may wonder why the proportion of players choosing $l$ and $L$ is not significantly different as can be seen in Figure $1(p-$ value $=0.5848$, likelihood ratio). The reason is that a small fraction of a large group (i.e., those choosing $h$ ), and a large fraction of a small group (i.e., those choosing $l$ ), changed actions between tasks. On aggregate, these effects cancel each other out.

An alternative explanation for the behavior described in Result 3 is that participants' "switching" is not due to beliefs about others' actions, but due to "conscience accounting". Gneezy et al. (2012) define conscience accounting as a "temporal inconsistency in social preferences" due to guilt for a previously unethical action. Although this would be consistent with the fact that the allocation task always followed the coordination game, we believe this explanation is unlikely to account fully for the behavior of other-regarding subjects reported in Result 3. The reason is that decision makers made 9 choices in Part 1 of the experiment. Given that they did not know the content of Part 2, one would expect that participants concerned about their conscience would be more other-regarding towards the end of Part 
1. However, as we saw, we observe no sequencing effects in Part 1. Further, in line with the fact that Result 3 reflects participants' beliefs, we note that selfish subjects (i.e., those choosing $h$ ) switched very infrequently to $L$ which suggests that participants believe they are more likely to be matched with a decision maker that will choose $H$. In any case, what is undisputed is that third-party externalities play a limited role in our experiment and that the majority of subjects is selfish in both parts of the experiment.

An open question from Experiment 1 is the following: Are subjects as willing to act against their self-interest to generate a large positive externality to a third party as they are to avoid a negative externality of the same magnitude? As noted, in Experiment 1, own-payoff maximization and efficiency concerns prescribe the same response to positive externalities. To answer the question above, we designed a second experiment where there is a tension between own-payoff maximization and generating positive externalities.

\section{Experiment 2}

\subsection{Experimental design and behavioral hypotheses}

This experiment follows closely the design and procedures in the first expreriment. The only differences are the basic game used for the coordination game and the allocation task, as well as the third-party externalities. The experiment was conducted in July 2012 . The 102 participants (68 decision-makers) were again students at the University of Melbourne that had not participated in the first experiment and they earned $\$ 38.14$ including a $\$ 10.00$ endowment, in Australian Dollars, while Players X and Y earned $\$ 42.21$ on average.

The basic coordination game, presented in Table 5, is similar to that used in Experiment 1. Players $\mathrm{X}$ and $\mathrm{Y}$ choose simultaneously between actions $H$ and $L$. If both take action $H$, then they earn 7 ECU each, while Person $\mathrm{Z}$ earns 4 ECU. If players $\mathrm{X}$ and $\mathrm{Y}$ take action $L$, then each receives 5 ECU and $\mathrm{Z}$ earns $z_{L}$ ECU. If $\mathrm{X}$ and $\mathrm{Y}$ fail to coordinate, all participants earn 0 ECU. Similar to Experiment 1, the third-party externality is defined as $E=z_{L}-4$. Like before, if it is common knowledge that players $\mathrm{X}$ and $\mathrm{Y}$ do not care about $z_{L}$, the game has two pure-strategy Nash equilibria, $(H, H)$ and $(L, L)$, with $(H, H)$ being payoff dominant. How does an efficiency-minded individual rank the two equilibria? An CR-individual will prefer $(L, L)$ to $(H, H)$, if and only if, $u_{i}\left(5,5, z_{L}\right) \geq u_{i}(7,7,4)$. This implies that

$$
\mathrm{CR}: z_{L} \geq 8+\frac{2}{\rho_{i}}, z_{L} \in(8, \infty)
$$

The intuition is that an individual that cares strongly about efficiency will prefer $(L, L)$ to 
$(H, H)$ as long as the total earnings in the former exceed that in the latter. This occurs when $z_{L} \geq 8$ and $E \geq 4$. As $z_{L}$ increases further, assuming a non-degenerate distribution of $\rho_{i}$, the condition above will be satisfied for an increasing number of efficiency-minded people who will choose $l$ over $h$.

This is the point, however, where allowing for maximin concerns (i.e., for $\gamma_{i} \neq 0$ in equation (2) as in the original model by Charness and Rabin, 2002) we obtain some interesting insights. In particular, in Appendix A, we show that the addition of maximin concerns in $i$ 's utility function implies that individuals in Experiment 2 will be less willing to act against their material interest by choosing $L$ to generate a large positive externality in Experiment 2 than they were to avoid a large negative externality of the same absolute size in Experiment 1. The intuition is simple. While negative externalities in Experiment 1 reduced both efficiency and the minimum earnings of a given person in the group, positive externalities in Experiment 2 influence only efficiency.

Hypothesis 4: Compared to the baseline treatment of $E=0$, participants will be less likely to take action $L$ to generate a positive third-party externality in Experiment 2, than they were to take action $L$ to avoid a negative externality of the same size in Experiment 1.

Hypothesis 4 seems intuitive in the sense that it reflects positional concerns: An individual will be less willing to pay to generate an externality of $E=20$, for example, when this would make them worse off than the third party, than they would be to avoid imposing an externality of $E=-20$ which would make the third party even worse off than they were. Given behavior in the first experiment, this hypothesis implies that overall we should observe few instances were decision makers choose $L$ across the board.

For experiment 2, we again studied the impact of a number of different values for $z_{L}$, In particular, $z_{L}=\{-8,-4,0,4,8,12,16,20,24\}$, which translates into a third-party externality $E=\{-12,-8,-4,0,4,8,12,16,20\}$. The rationale for choosing these values is that we wanted to allow for positive externalities of the same absolute size as the negative externalities in the first experiment, while also allowing for some negative externalities for symmetry across experiments. Clearly, neither a selfish nor an efficiency-minded individual will prefer $(L, L)$ to $(H, H)$ when $E<4$. Inequality averse individuals would also not prefer $(L, L)$ to $(H, H)$ when $E<0$ as they would suffer from guilt as well as from a lower material payoff. As a benchmark for comparison, we once again consider the case with $z_{L}=4$ and $E=0$.

\subsection{Results}

Result 4: Neither positive nor negative externalities affect choices in the coordination game. 
SUPPORT: The black columns in Figure 4 present the probability a decision maker selects $L$ in the coordination game as a function of the third-party externality $\left(E=z_{L}-4\right)$. As can be seen, as the size of the positive externality increases, the probability that a decision maker takes action $L$ does not appear to increase systematically or subtantially. If we repeat the regression analysis presented in Table 3 for Experiment 2, all independent variables have small and statistically insignificant coefficients. This analysis is available in the supplementary material.

It should be clear from Result 4 that neither negative nor positive third-party externalities affect the rate of coordination failure or efficiency. For brevity, the supporting analysis is moved in the supplementary material. Next we explore the relation between decisions in the allocation task and in the coordination game.

Result 5: Almost all participants choosing allocation $h$ chose action $H$ in the coordination game. A large majority of the participants who chose allocation l, chose action $H$ in the coordination game.

SUPPORT: Figure 5 presents the probability an individual choosing $l(h)$ in the allocation task will choose $H(L)$ in the coordination game, as a function of the externality. As can be seen, it is individuals who choose $l$ in the allocation task that are much more likely to switch and choose $H$ in the coordination game, than individuals choosing $h$ are to choose $L$. Like with Experiment 1, to obtain statistical support, we perform separate non-parametric tests for each value of the positive externality to compare the likelihood an individual choosing $l(h)$ will "switch" in the coordination game (there are are two few observations of people choosing $l$ when $E<0)$. For the largest externality $(E=20)$, of the 56 individuals who selected $h, 50(89 \%)$ individuals chose $H$ in the corresponding coordination game. In sharp contrast, only 3 of 12 individuals (25\%) choosing $l$ in the allocation task decided to take action $L$ in the coordination game. A Fisher-exact test indicates that players' allocation task action has significant explanatory power for "matching" their actions $(p$-value $<0.001)$. We also reject similar hypotheses for all other positive externalities at the $5 \%$ level.

Figure 5 presents graphically the probability an individual choosing $l(h)$ will choose $H$ $(L)$ in the coordination game as a function of the externality. Clearly, individuals choosing $l$ in the allocation task are much more likely to choose $H$ in the coordination game, than individuals choosing $h$ are to choose $L$.

Result 6: In line with Hypothesis 4, decision makers in the coordination game appear to be more willing to incur a cost to avoid large negative externalities that reduce efficiency in Experiment 1 than they are to generate large positive externalities that increase it in Experiment 2. 
SUPPORT: In Figure 4, we see that only 9 out of 68 decision makers (i.e., $13.2 \%$ of cases) chose action $L$ when $E=20$. In contrast, 20 of the 70 decision makers in Figure 1 (i.e., $28.6 \%$ of cases) were willing to incur a cost by choosing $L$ to avoid imposing a negative externality of the same (absolute) size to the third party (i.e., $E=-20$ ). This difference is statistically significant (Fisher exact, one-sided, $p$-value $=0.022$ ). The difference, albeit smaller, is also significant in the allocation task $(p$-value $=0.093)$. The difference for smaller absolute values of the externality fails to be significant, although the averages suggest that this may be due to our sample size.

\section{Mixture model}

The aggregate patterns seen in the two experiments indicate the concerns for one's own income far outweigh social concerns, while concerns for efficiency appear to weigh more in decisions than concerns for equality in payoffs. In this section, we discuss a mixture model using the data from both experiments and estimating how many people could be classified as selfish, welfare-minded (a la Charness and Rabin, 2002; CR) and inequality averse (a la Fehr and Schmidt, 1999; FS), as well as the parameters for the two models of social preferences.

Using the data from the allocation task, we estimate a simple distribution of preferences by assuming that players use a logistic choice function. In the full model, we assume that there is one "selfish" type, one CR type, and one FS type; and estimate both the fractions of participants that are these types, as well as the parameters of the CR and FS types. (We normalize the CR utility function by dividing through by $1-\lambda$. This ensures that the derivatives of all utility functions with respect to own payoff are the same.) Let $\boldsymbol{\theta}$ be a vector containing all parameters in the model. This includes parameters in the utility functions, the mixing probabilities of the types, and a logistic noise term. The probability that a player with utility function $u_{j}(\mathbf{x} ; \boldsymbol{\theta})$ chooses $l$ for a given externality is:

$$
\operatorname{Pr}\left[a_{i, z}=l \mid \boldsymbol{\theta}, j\right]=\frac{\exp \left(\mu u_{j}\left(5,5, z_{L} ; \boldsymbol{\theta}\right)\right)}{\exp \left(\mu u_{j}\left(5,5, z_{L} ; \boldsymbol{\theta}\right)\right)+\exp \left(\mu u_{j}\left(7,7, z_{H} ; \boldsymbol{\theta}\right)\right)}, \quad j \in\{\text { selfish, CR, FS }\}
$$

where $a_{i, z}$ is the action taken by participant $i$ when Person Z's payoffs were $z$, and $\mu>0$ is the logistic noise term. From this we can construct a likelihood of observing the player's actions in the coordination game conditional on having utility function $u_{j}(\cdot ; \boldsymbol{\theta})$ :

$$
\ell_{i}(\boldsymbol{\theta}, j)=\prod_{\forall z} \operatorname{Pr}\left[a_{i, z} \mid \boldsymbol{\theta}, j\right]
$$

Incorporating the mixing probabilities $\left\{p_{j}\right\}$ and summing over all observations to get the 
overall log-likelihood:

$$
\mathcal{L}(\boldsymbol{\theta})=\sum_{i=1}^{n} \log \left[\sum_{\forall j} p_{j} \ell_{i}(\boldsymbol{\theta}, j)\right]
$$

We then estimate the parameters thus:

$$
\hat{\boldsymbol{\theta}}=\arg \max _{\boldsymbol{\theta} \in \Theta} \mathcal{L}(\boldsymbol{\theta})
$$

where $\Theta$ is the set of allowable parameters (i.e., parameters satisfying $\mu>0, p_{j} \in[0,1]$, etc.). In fact, we estimate transformations of the parameters which allow for an unconstrained optimization.

The results of the estimation indicate that the behavior of a surprisingly large percentage of our participants (77\%) is best explained by assuming that they only care to maximize their earnings. The Charness and Rabin (2002) model best accounts for the behavior of $19.4 \%$ of decision makers, while $3.6 \%$ of individuals behave in line with the Fehr and Schmidt (1999) model of inequality aversion. Amongst the CR types, social concerns are rather weak with a $\lambda=0.25$, which means that own-income weighs three times as much as social concerns. The estimate also indicates that $\delta=0.06$ implying that efficiency concerns have much more gravitas in decision making than maximin concerns. Amongst the FS types, given the restriction that $\alpha_{i} \geq \beta_{i}$, we estimate that $\alpha_{i}=1.09$ and $\beta_{i}=1.00$. Given that these values

are multiplied by $\frac{1}{n-1}$ in the Fehr-Schmidt model (i.e., divided by 2 ), the weight on envy is 0.55 times that of own-income, and on guilt 0.5 times.

\section{Conclusion}

Motivated by evidence that individuals care about the welfare of others, we set out to explore how third-party externalities affect tacit coordination. We honestly believed that the strategic uncertainty agents face in the coordination game would make decision makers take into account the third-party externalities, at least when they were large relative to the sacrifice required. Looking at the data however, it is clear we underestimated the power of selfishness. More than 70 percent of participants in our experiments were willing to take an action that would increase their earnings by a small amount, even if by doing so they would make an innocent bystander substantially worse off by generating a negative externality ten times as large, increase inequality in payoffs and reduce efficiency. Even fewer people were willing to take actions that would reduce their own earnings as the size of the externality became smaller. Not surprisingly then, we found that it was individuals willing to sacrifice some of their earnings in favor of the third party that adjusted their behavior 
to the preferences of selfish decision makers and chose the action that would (potentially) maximize their own earnings; not the other way round.

This is not to suggest that social preferences do not matter or that third-party externalities have no impact on equilibrium selection. Between 20 and 30 percent of participants in our experiment appear to have social concerns. The aggregate patterns observed are best captured by the model of Charness and Rabin (2002) which assumes that, in addition to caring for their own material payoff, some individuals care for efficiency and increasing the lowest payoff in one's reference group. In particular, this model was able to provide an explanation for the asymmetric effect of externalities in our experiment, that is, why decision makers may be willing to incur a cost to avoid a negative externality in Experiment 1, but not to create a large positive externality in Experiment 2. Our data is not consistent with the Fehr-Schmidt (1999) model of inequality aversion which predicts that individuals dislike large positive externalities even more than large negative externalities. This is in line with evidence from games with unique equilibria showing that the predictive power of this model is limited when intentionality plays no role (e.g., Blanco et al., 2011; Charness and Kuhn, 2007; Kagel and Wolfe, 2001), as is the case in our experiment. It is also not in line with previous evidence on third-party externalities from social dilemma and bargaining experiments which suggest that third parties are not ignored when they are better off than decision makers (Engel and Rockenbach, 2011; McDonald et al., 2013). The fact that efficiency concerns seem to matter more than those for equality is consistent with the findings in several recent studies (e.g., Balafoutas et al. 2012; Cabrales et al., 2010; Charness and Grosskopf, 2001; Charness and Rabin, 2002; Cox \& Sadiraj, 2012; Engelmann \& Strobel, 2004; Faravelli et al., 2013; Fisman et al., 2007; Kritikos \& Bolle, 2001).

Given our motivating examples at the start of the paper, one may wonder what our experimental results can tell us about similar situations outside the lab where agents - whether they are governments, organizations or individuals - try to coordinate and in doing so impose externalities on inactive agents. Obviously, one needs to be cautious when generalizing from a laboratory experiment. Even though the evidence presented in Cleave et al. (2013) and Falk et al. (2013) suggests that the results from our sample may generalize to a more general population, ${ }^{15}$ many of the decisions in the examples used to motivate our paper will be taken $(i)$ by groups of individuals, $(i i)$ whose members will have been selected through highly competitive processes and (iii) will have the power to act on behalf of others. All three factors have been shown to reduce other-regarding behavior (e.g., Charness and Sutter, 2012; Erkal et al., 2011; Hamman et al., 2010, respectively). Further, outside the lab, there

\footnotetext{
${ }^{15}$ Using a large-scale experiment in the same lab we used for this experiment and around the same time, Cleave et al. (2013) found no evidence that the social (or risk) preferences of voluteers for lab experiments are different than those of the population from which they were recruited.
} 
is bound to be less transparency about the agents' alternatives and their choices which may further reduce the salience of third-party externalities. Therefore, we believe that there are reasons to be concerned that third-party externalities and strategic uncertainty will not be sufficient to dissuade firms from trying to collude or encourage countries to try to coordinate on policies that improve efficiency when this is against their self-interest. The standard model which assumes that agents care solely for their own welfare without any distributional concerns may provide a good approximation of actual behavior outside the lab in such cases.

Of course, further studies are needed before we have a better understanding of when third-party externalities may be ignored from our theoretical analysis as a factor influencing decisions. After all, a sizable minority of subjects does take them eventually into account in our experiment. An interesting topic for future research given our findings is how third-party externalities affect tacit coordination when the private incentives of the decision makers are not aligned or in pure coordination games where decision makers simply wish to coordinate without a preference otherwise for one of the strategies. Further, it would be interesting to investigate our set up in different samples. For example, in strongly pro-social samples, selfish decision makers may be the ones adjusting to the preferences of other-regarding decision makers. However, whether this is the case is an empirical question. Finally, it could be interesting to explore whether certain policy interventions can take advantage of the strategic uncertainty and make decision makers internalize third-party externalities, and improve welfare. Given the economic and social significance of third-party externalities, as well as the attention received by models of social preferences, we believe that investigating the limits of our conclusions is important.

\section{References}

[1] Andreoni, James, Marco Castillo, and Ragan Petrie. 2003. "What Do Bargainers' Preferences Look Like? Experiments with a Convex Ultimatum Game." American Economic Review, 93 (3): 672-685.

[2] Balafoutas, Loukas, Rudolf Kerschbamer, and Matthias. Sutter. 2012. "Distributional preferences and competitive behavior." Journal of Economic Behavior and Organization, 83: 125-135.

[3] Blanco, Mariana, Dirk Engelmann, Alexander Koch, and Hans-Theo Normann. 2010. "Belief Elicitation in Experiments: Is there a Hedging Problem?" Experimental Economics, 13: 412-438. 
[4] Blanco, Mariana, Dirk Engelmann, and Hans Theo Normann. 2011. "A Within-Subject Analysis of Other-Regarding Preferences." Games and Economic Behavior, 72(2): 321338.

[5] Bigoni, Maria, Stefania Bortolotti, Marco Casari, Diego Gambetta. 2013. "It Takes Two to Cheat: An Experiment on Derived Trust." forthcoming European Economic Review.

[6] Bolton, Gary E., and Axel Ockenfels. 2000. "ERC: A Theory of Equity, Reciprocity, and Competition." American Economic Review, 90(1): 166-193.

[7] Cabrales, Antonio, Raffaele Miniaci, Marco Piovesan, and Giovanni Ponti. 2010. "Social Preferences and Strategic Uncertainty: An Experiment on Markets and Contracts." American Economic Review, 100: 2261-2278.

[8] Camerer, C.F., 2003. Behavioral Game Theory: Experiments in Strategic Interaction. Russell Sage, New York.

[9] Canzoneri, Matthew B., Robert E. Cumby, and Behzad T. Diba. 2005. "The Need for International Policy Coordination: What's Old, What's New, What's Yet to Come?" Journal of International Economics, 66: 363- 384.

[10] Cason, Timothy, Vai-Lam Mui. 2007. "Communication and Coordination in the Laboratory Collective Resistance Game." Experimental Economics, 10: 251-267.

[11] Charness, Gary, and Matthew Rabin. 2002. "Understanding Social Preferences with Simple Tests." The Quarterly Journal of Economics, 117(3): 817-869.

[12] Charness, Gary and Brit Grosskopf. 2001. "Relative Payoffs and Happiness: An Experimental Study." Journal of Economic Behavior \&3 Organization, 45: 301-328.

[13] Charness, Gary and Peter Kuhn. 2007. "Does Pay Inequality Affect Worker Effort? Experimental Evidence." Journal of Labor Economics, 25 (4): 693-723.

[14] Charness, Gary and Matthias Sutter. 2012. "Groups Make Better Self-Interested Decisions." Journal of Economic Perspectives, 26(3): 157-76.

[15] Chmura, Thorsten, Sebastian Kube, Thomas Pitz, and Clemens Puppe. 2005. "Testing (beliefs about) Social Preferences: Evidence from an Experimental Coordination Game." Economics Letters, 88: 214-220.

[16] Cleave, Blair L., Nikos Nikiforakis, and Robert Slonim. 2012. "Is there Selection Bias in Laboratory Experiments? The case of Social and Risk Preferences." forthcoming Experimental Economics. 
[17] Cooper, David, J. and John H., Kagel. 2013. "Other Regarding Preferences: A Selective Survey of Experimental Results", forthcoming in Handbook of Experimental Economics Vol. 2.

[18] Cooper, Russell, and Andrew John. 1988. "Coordinating Coordination Failures in Keynesian Models." The Quarterly Journal of Economics, 103 (3): 441-463.

[19] Cox, James C. and Vjollca Sadiraj. 2012. "Direct Tests of Individual Preferences for Efficiency and Equity." Economic Inquiry, 50 (4): 920 - 931.

[20] Crawford, Vincent P., Uri Gneezy, and Yuval Rottenstreich. 2008. "The Power of Focal Points Is Limited: Even Minute Payoff Asymmetry May Yield Large Coordination Failures." American Economic Review, 98(4): 1443-1458.

[21] Ellman, Matthew and Paul Pezanis-Christou. 2010. "Organisational Structure, Communication and Group Ethics." American Economic Review, 100(5), 2478-2491.

[22] Engel, Christoph, and Bettina Rockenbach. 2011. "We are Not Alone: The Impact of Externalities on Public Good Provision." SSRN eLibrary.

[23] Engel, Christoph, and Lilia Zhurakhovska. 2012. "Harm on an Innocent Outsider as a Lubricant of Cooperation - An Experiment." Max Planck Institute for Research on Collective Goods 2012/2.

[24] Engelmann, Dirk and Martin Strobel. 2004. "Inequality Aversion, Efficiency, and Maximin Preferences in Simple Distribution Experiments." American Economic Review, 94: $857-869$.

[25] Erkal, Nisvan, Lata Gangadharan, and Nikos Nikiforakis. 2011. "Relative Earnings and Giving in a Real Effort Experiment" American Economic Review, 101(7), 3330-3348.

[26] Falk, Armin, Stephen Meier, and Christian Zehnder (2013). "Do Lab Experiments Misrepresent Social Preferences? The Case of Self-Selected Student Samples." forthcoming Journal of the European Economic Association.

[27] Faravelli, Marco, Oliver Kirchkamp, and Helmut Rainer. 2013. "The Effect of Power Imbalances on Incentives to Make Non-Contractible Investments." forthcoming European Economic Review.

[28] Farrell, Alexander E., and Daniel Sperling. 2007. "A Low-Carbon Fuel Standard for California, Part 2: Policy Analysis." Institute of Transportation Studies, UC Davis. 
[29] Fehr, Ernst, and Klaus M. Schmidt. 1999. "A Theory of Fairness, Competition and Cooperation." Quarterly Journal of Economics, 114(3): 817-868.

[30] Fisman, Raymond, Shachar Kariv, and Daniel Markovits. 2007. "Individual Preferences for Giving." American Economic Review, 97: 1858-1876.

[31] Fischbacher, Urs. 2007. "z-Tree: Zurich Toolbox for Ready-Made Economic Experiments." Experimental Economics, 10: 171-178.

[32] Genicot, Garance, and Debraj Ray. 2006. "Contracts and Externalities: How Things Fall Apart." Journal of Economic Theory 131: 71 - 100.

[33] Gneezy, Uri, Alex Imas, Kristóf Madarász. 2012. "Conscience Accounting: Emotional Dynamics and Social Behavior." LSE STICERD - Theoretical Economics Paper Series Working Paper No. 563.

[34] Greiner, Ben. 2004. "An Online Recruitment System for Economic Experiments." Forschung und wissenschaftliches Rechnen 2003. GWDG Bericht 63, Gottingen : Ges. fur Wiss. Datenverarbeitung, 63: 79-93.

[35] Güth, Werner, and Eric van Damme. 1998. "Information, Strategic Behavior, and Fairness in Ultimatum Bargaining: An Experimental Study,." Journal of Mathematical Psychology, 42(2-3): 227-247.

[36] Hamman, John R., George Loewenstein, and Roberto A.Weber. 2010. "Self-interest through Delegation: An Additional Rationale for the Principal-agent Relationship." American Economic Review, 100: 1826-46.

[37] Kagel, John, and Katherine Wolfe. 2001. "Tests of Fairness Models Based on Equity Considerations in a Three-Person Ultimatum Game." Experimental Economics, 4(3): 203-219.

[38] Kritikos, Alexander and Friedel Bolle. 2001. "Distributional Concerns: Equity- or Efficiency Oriented?" Economics Letters, 73: 333-338.

[39] McDonald, Ian, Nikos Nikiforakis, Nilss Olekalns, and Hugh Silby. 2013. "Social Comparisons and Reference Group Formation: Some Experimental Evidence." Games and Economic Behavior, 79, 75-89.

[40] Mehta, Judith, Chris Starmer, and Robert Sugden. 1994. "The Nature of Salience: An experimental Investigation of Pure Coordination Games." American Economic Review, 84(3): 658-673. 
[41] Segal, Ilya. 2003. "Coordination and Discrimination in Contracting with Externalities: Divide and Conquer? Journal of Economic Theory 113: 147-181.

[42] Sweeting, Andrew. 2009. "The Strategic Timing Incentives of Commercial Radio Stations: An Empirical Analysis Using Multiple Equilibria." RAND Journal of Economics, 40(4): 710-742.

[43] Van Huyck, John B., Raymond C. Battalio, and Richard O. Beil. 1990. "Tacit Coordination Games, Strategic Uncertainty, and Coordination Failure." American Economic Review, 80(1): 234-248.

[44] Vits, C. and G. Thesing. 2011. Trichet Proposes Euro-Area Finance Ministry to Coordinate Fiscal Policies. Bloomberg. http://www.bloomberg.com/news/2011-06-02/trichetproposes-euro-area-finance-ministry-to-coordinate-fiscal-policies.html 


\section{Appendix A}

In this appendix, we show that the $n$-person model of Charness and Rabin (2002, p. 852) predicts that, all else equal, decision makers, on average, will be more likely to incur a cost by choosing $L$ to avoid imposing a negative externality in Experiment 1, than individuals in Experiment 2 will be to generate a large positive externality of the same size that leaves the third party with a higher payoff than the decision makers.

As explained in the paper, the utility function of a decision maker is assumed to be given by:

$$
V_{i}(\mathbf{x})=\left(1-\lambda_{i}\right) x_{i}+\lambda_{i}\left[\delta_{i} \min \{\mathbf{x}\}+\left(1-\delta_{i}\right) \sum_{j=1}^{n} x_{j}\right], \quad\left(\lambda_{i}, \delta_{i}\right) \in[0,1]^{2}
$$

If $\lambda_{i} \neq 1$, we can represent these preferences like this:

$$
u_{i}(\mathbf{x})=x_{i}+\gamma_{i} \min \{\mathbf{x}\}+\rho_{i} \sum_{j=1}^{n} x_{j}, \quad \gamma_{i}, \rho_{i} \geq 0
$$

That is, $\gamma_{i}=\frac{\lambda_{i} \delta_{i}}{1-\lambda_{i}}, \quad \rho_{i}=\frac{\lambda_{i}\left(1-\delta_{i}\right)}{1-\lambda_{i}}$.

Preferring $L$ in Experiment 1 is equivalent to:

$$
\begin{gathered}
5+14 \rho+4 \gamma \geq 7+\rho\left(14+z_{H}\right)+\gamma \min \left\{z_{H}, 7\right\} \\
\Longleftrightarrow 5+14 \rho+4 \gamma \geq 7+\rho\left(18+E_{H}\right)+\gamma \min \left\{E_{H}+4,7\right\} .
\end{gathered}
$$

Preferring $L$ in Experiment 2 is equivalent to:

$$
\begin{gathered}
5+\rho\left(10+z_{L}\right)+\gamma \min \left\{5, z_{L}\right\} \geq 7+18 \rho+4 \gamma \\
\Longleftrightarrow 5+\rho\left(14+E_{L}\right)+\gamma \min \left\{5, E_{L}+4\right\} \geq 7+18 \rho+4 \gamma
\end{gathered}
$$

Assuming that $E_{H}+4 \leq 7$ (i.e., the externality in Experiment 1 is such that Person Z will have the lowest payoff) and $E_{L}+4 \geq 5$ (i.e., the externality in Experiment 2 is such that Person $\mathrm{Z}$ will have the highest payoff $),{ }^{16}$ equations $((\mathrm{A} 1))$ and $((\mathrm{A} 2))$ can be respectively written as:

\footnotetext{
${ }^{16}$ Given the values for $E_{H}$ and $E_{L}$ used in our experiments, the first condition refers to the negative externality imposed by choosing $H$ in Experiment 1, while the second condition refers to the positive externality imposed by choosing $L$.
} 


$$
\begin{gathered}
5+14 \rho+4 \gamma \geq 7+\rho\left(18+E_{H}\right)+\gamma\left(E_{H}+4\right) \\
\Longleftrightarrow-\rho\left(4+E_{H}\right)-\gamma E_{H} \geq 2 \\
5+\rho\left(14+E_{L}\right)+5 \gamma \geq 7+18 \rho+4 \gamma \\
-\rho\left(4-E_{L}\right)+\gamma \geq 2
\end{gathered}
$$

Let $E=\left\|E_{L}\right\|=\left\|E_{H}\right\|$ and assume that $E_{H} \leq 0 \leq E_{L}$. (We show at the end of this appendix that this is not a restriction given the treatments considered, i.e., that $E_{H}+4 \leq 7$ and $E_{L}+4 \geq 5$.) Equations ((A1)) and ((A2)) can be rewritten as:

$$
\begin{array}{rr}
-\rho(4-E)+\gamma E \geq 2 & \text { (experiment } 1) \\
-\rho(4-E)+\gamma \geq 2 & \text { (experiment 2) }
\end{array}
$$

For any $E \geq 1$ :

$$
-\rho(4-E)+\gamma E \geq-\rho(4-E)+\gamma
$$

(strict if $\gamma>0$ ). Therefore choosing $l$ for $E_{L}=E \geq 1$ in Experiment 2 implies choosing $l$ for $E_{H}=-E$ in Experiment 1.

The $E_{H}+4 \leq 7$ and $E_{L}+4 \geq 5$ restrictions are now:

$$
\begin{array}{cl}
-E+4 \leq 7, \quad & E+4 \geq 5 \\
-3 \leq E, \quad & E \geq 1
\end{array}
$$

So $E \geq 1$ is not an additional restriction (i.e., we just require that $E$ is such that $-E$ is the minimum payoff in Experiment 1, and $E$ is not the minimum payoff in Experiment 2). 
Table 1 - The basic coordination game in Experiment 1

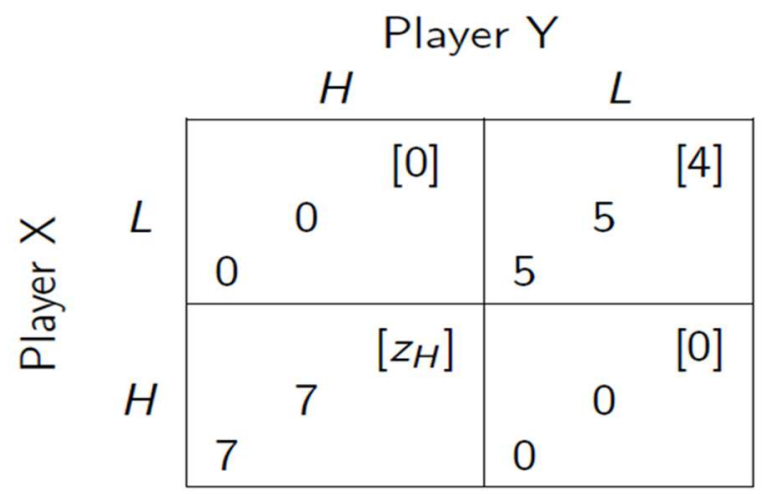

Table 2 - The allocation task in Experiment 1

\begin{tabular}{cccccc}
\hline \multicolumn{3}{c}{ Allocation $\boldsymbol{h}$} & \multicolumn{3}{c}{ Allocation $\boldsymbol{l}$} \\
$\mathbf{X}$ & $\mathbf{Y}$ & $\mathbf{Z}$ & $\mathbf{X}$ & $\mathbf{Y}$ & $\mathbf{Z}$ \\
\hline 7 & 7 & $\boldsymbol{z}$ & 5 & 5 & 4 \\
\hline
\end{tabular}


Table 3 - The impact of third-party externalities on the probability to select action $L$ in Experiment 1

\begin{tabular}{|c|c|c|c|}
\hline & $(1)$ & $(2)$ & $(3)$ \\
\hline (Absolute) Negative Externality & $\begin{array}{c}0.156^{* * *} \\
(0.0444)\end{array}$ & $\begin{array}{c}0.158^{* * *} \\
(0.0283)\end{array}$ & \\
\hline Positive Externality & $\begin{array}{c}0.0541 \\
(0.104)\end{array}$ & $\begin{array}{c}0.0481 \\
(0.0523)\end{array}$ & \\
\hline $\mathrm{E}=-20$ (dummy) & & & $\begin{array}{c}3.707^{* * *} \\
(0.885)\end{array}$ \\
\hline $\mathrm{E}=-16$ (dummy) & & & $\begin{array}{c}2.916^{\text {*** }} \\
(0.882)\end{array}$ \\
\hline $\mathrm{E}=-12($ dummy $)$ & & & $\begin{array}{c}2.916^{* * *} \\
(0.882)\end{array}$ \\
\hline $\mathrm{E}=-8$ (dummy) & & & $\begin{array}{c}1.902^{*} \\
(0.903)\end{array}$ \\
\hline $\mathrm{E}=-4$ (dummy) & & & $\begin{array}{c}0.878 \\
(0.969)\end{array}$ \\
\hline $\mathrm{E}=4($ dummy $)$ & & & $\begin{array}{c}1.188 \\
(0.942)\end{array}$ \\
\hline $\mathrm{E}=8($ dummy $)$ & & & $\begin{array}{c}1.188 \\
(0.942)\end{array}$ \\
\hline $\mathrm{E}=12$ (dummy) & & & $\begin{array}{c}0.878 \\
(0.969)\end{array}$ \\
\hline constant & $\begin{array}{c}-3.948^{* * *} \\
(0.841)\end{array}$ & $\begin{array}{c}-4.777^{* * *} \\
(0.619)\end{array}$ & $\begin{array}{c}-5.385^{* * *} \\
(0.927)\end{array}$ \\
\hline Number of observations & 210 & 630 & 630 \\
\hline Log likelihood & -76.55 & -179.4 & -177.6 \\
\hline Decisions & First 3 & All & All \\
\hline $\ln \operatorname{sig} 2 \mathrm{u}$ & 0.933 & $1.620^{* * *}$ & $1.635^{* * *}$ \\
\hline cons & $(0.707)$ & $(0.379)$ & $(0.378)$ \\
\hline
\end{tabular}


Table 4 - The impact of third-party externalities on the earnings of the decision makers and overall efficiency in Experiment 1

\begin{tabular}{|c|c|c|c|c|c|c|}
\hline & $(1)$ & $(2)$ & (3) & $(4)$ & $(5)$ & (6) \\
\hline $\begin{array}{l}\text { (Absolute) Negative } \\
\text { Externality }\end{array}$ & $\begin{array}{c}-0.255^{* * *} \\
(0.0514)\end{array}$ & $\begin{array}{c}-0.247^{* * *} \\
(0.0314)\end{array}$ & & $\begin{array}{c}-0.764^{* * *} \\
(0.0568)\end{array}$ & $\begin{array}{c}-0.843^{* * *} \\
(0.0386)\end{array}$ & \\
\hline Positive Externality & $\begin{array}{r}-0.0767 \\
(0.119)\end{array}$ & $\begin{array}{l}-0.0902 \\
(0.0544)\end{array}$ & & $\begin{array}{c}0.933^{* * *} \\
(0.132)\end{array}$ & $\begin{array}{l}0.868^{* * *} \\
(0.0668)\end{array}$ & \\
\hline $\mathrm{E}=-20$ (dummy) & & & $\begin{array}{c}-5.143^{* * *} \\
(0.795)\end{array}$ & & & $\begin{array}{c}-16.80^{* * *} \\
(0.971)\end{array}$ \\
\hline $\mathrm{E}=-16($ dummy $)$ & & & $\begin{array}{c}-4.114^{* * *} \\
(0.795)\end{array}$ & & & $\begin{array}{c}-15.31^{* * *} \\
(0.971)\end{array}$ \\
\hline $\mathrm{E}=-12($ dummy $)$ & & & $\begin{array}{c}-3.429^{* * *} \\
(0.795)\end{array}$ & & & $\begin{array}{c}-12.23^{* * *} \\
(0.971)\end{array}$ \\
\hline $\mathrm{E}=-8$ (dummy) & & & $\begin{array}{l}-1.714^{*} \\
(0.795)\end{array}$ & & & $\begin{array}{c}-8.571^{* * *} \\
(0.971)\end{array}$ \\
\hline $\mathrm{E}=-4($ dummy $)$ & & & $\begin{array}{l}-0.800 \\
(0.795)\end{array}$ & & & $\begin{array}{c}-4.571^{* * *} \\
(0.971)\end{array}$ \\
\hline $\mathrm{E}=4$ (dummy) & & & $\begin{array}{l}-1.200 \\
(0.795)\end{array}$ & & & $\begin{array}{c}1.886 \\
(0.971)\end{array}$ \\
\hline $\mathrm{E}=8$ (dummy) & & & $\begin{array}{l}-1.200 \\
(0.795)\end{array}$ & & & $\begin{array}{c}5.314^{* * *} \\
(0.971)\end{array}$ \\
\hline $\mathrm{E}=12($ dummy $)$ & & & $\begin{array}{l}-0.800 \\
(0.795)\end{array}$ & & & $\begin{array}{c}9.600^{* * *} \\
(0.971)\end{array}$ \\
\hline constant & $\begin{array}{c}12.64^{* * *} \\
(0.666)\end{array}$ & $\begin{array}{c}13.04^{* * *} \\
(0.475)\end{array}$ & $\begin{array}{c}13.20^{* * *} \\
(0.638)\end{array}$ & $\begin{array}{c}15.20^{* * *} \\
(0.717)\end{array}$ & $\begin{array}{c}15.75^{* * *} \\
(0.500)\end{array}$ & $\begin{array}{c}16.97^{* * *} \\
(0.720)\end{array}$ \\
\hline $\begin{array}{l}\text { Number of } \\
\text { observations }\end{array}$ & 210 & 630 & 630 & 210 & 630 & 630 \\
\hline R-squared (overall) & 0.107 & 0.0844 & 0.0887 & 0.636 & 0.680 & 0.685 \\
\hline Role of player & $\mathrm{X}$ and $\mathrm{Y}$ & $\mathrm{X}$ and $\mathrm{Y}$ & $\mathrm{X}$ and $\mathrm{Y}$ & All & All & All \\
\hline Decisions & First 3 & All & All & First 3 & All & All \\
\hline
\end{tabular}


Table 5 - The basic coordination game in Experiment 2

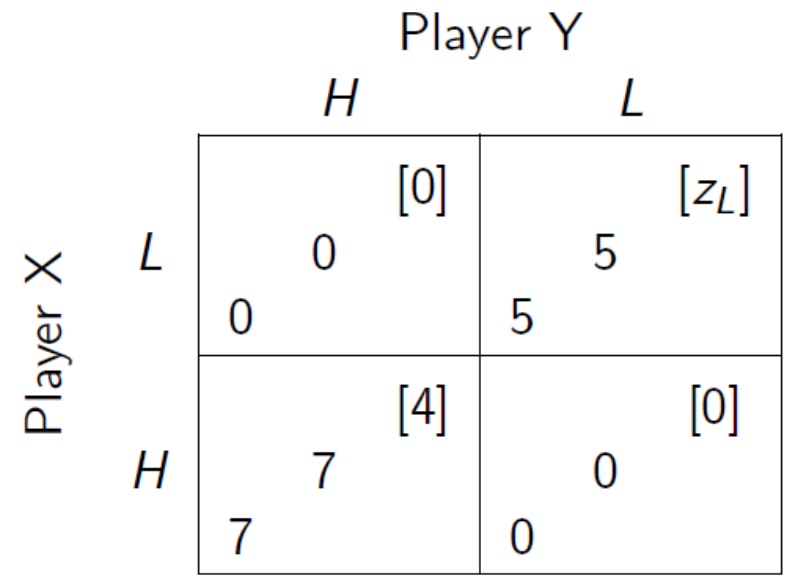


Figure 1 - The probability of taking action $L(1)$ in the coordination game (allocation task) in Experiment 1

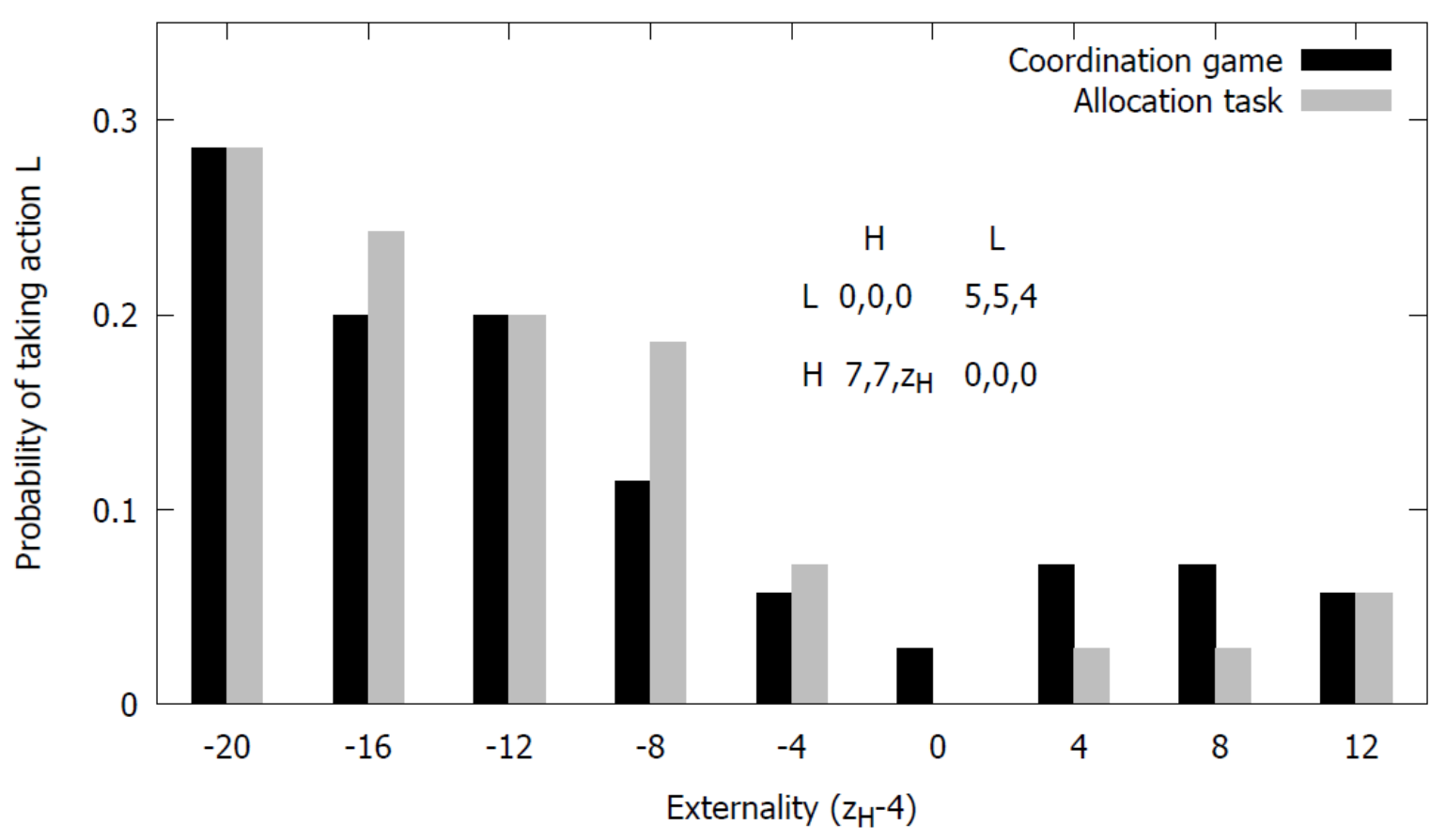

Figure 2 - The probability of coordination success in Experiment 1

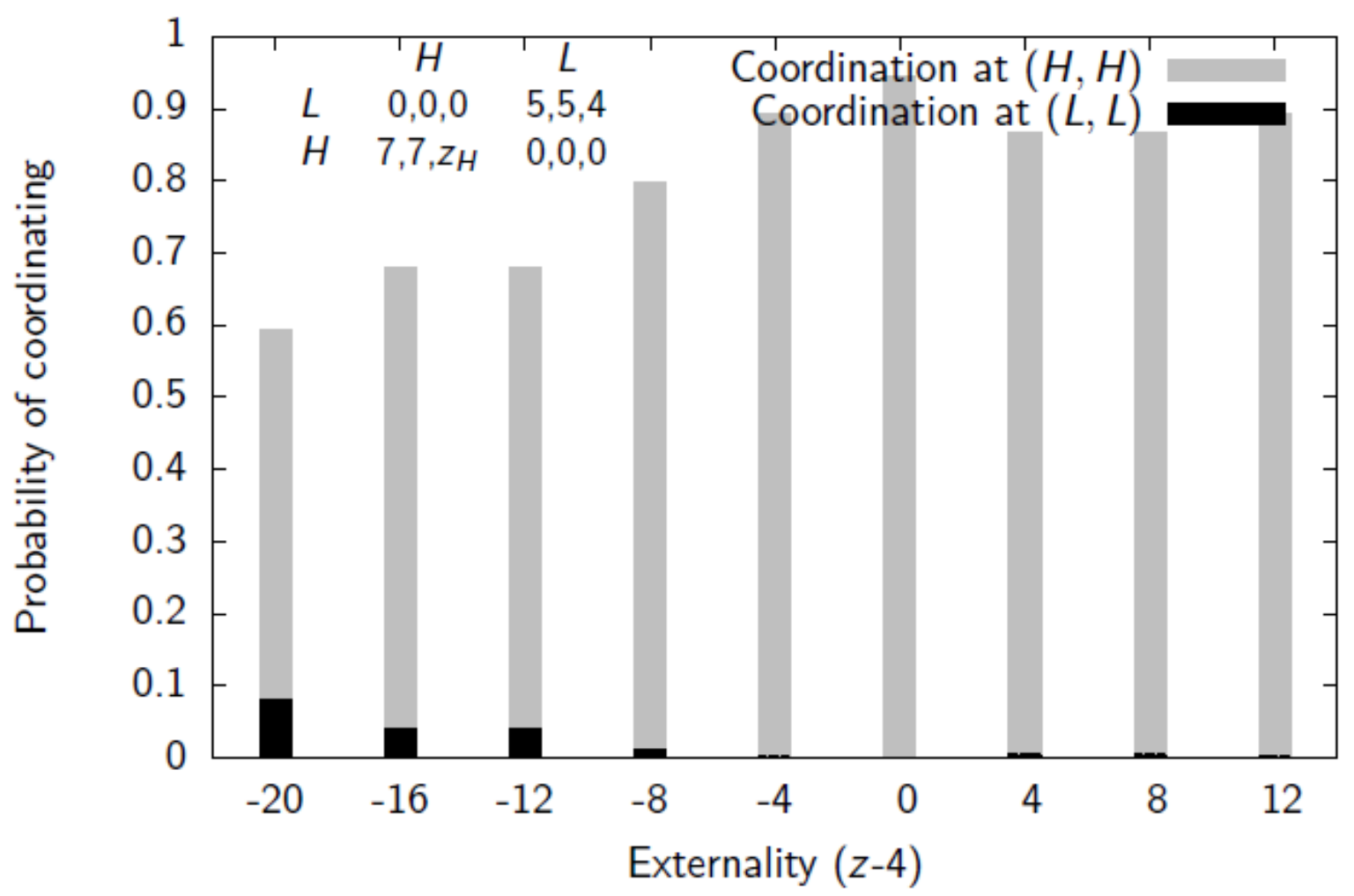


Figure 3 - The probability of "switching" between the allocation task and the coordination game in Experiment 1

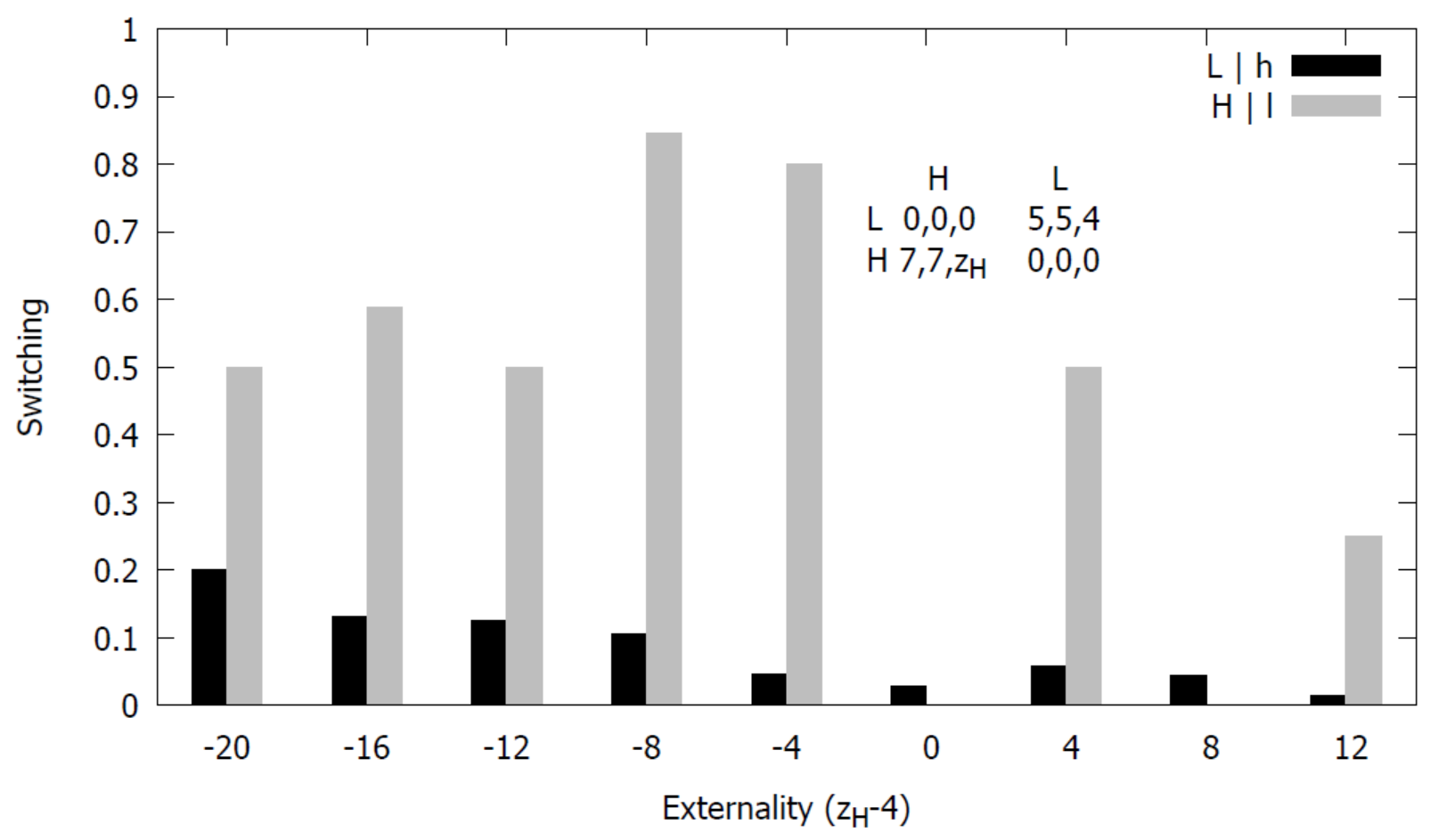

Figure 4 - The probability of taking action $L$ (I) in the coordination game (allocation task) in Experiment 2

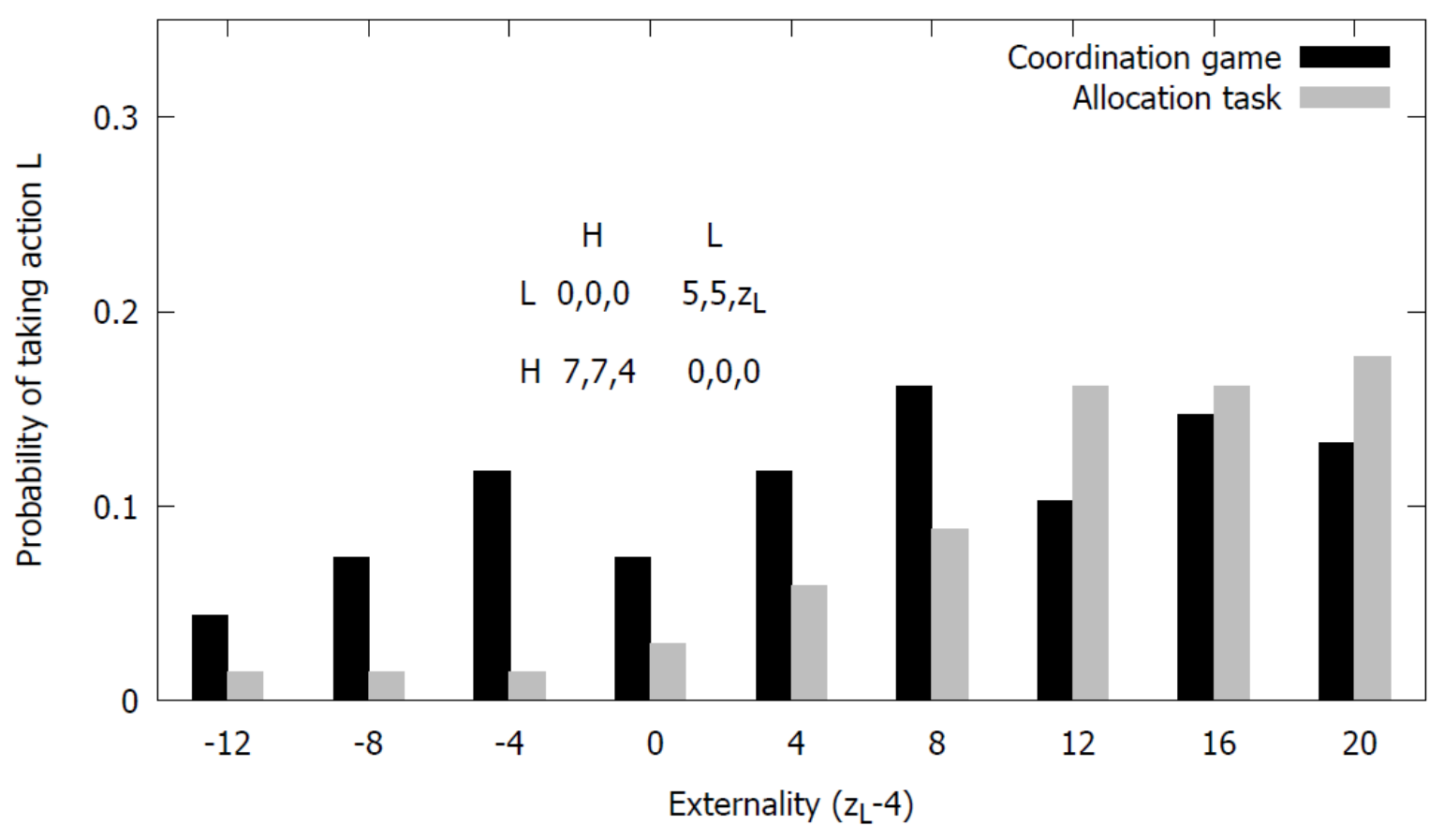


Figure 5 - The probability of "switching" between the allocation task and the coordination game in Experiment 2

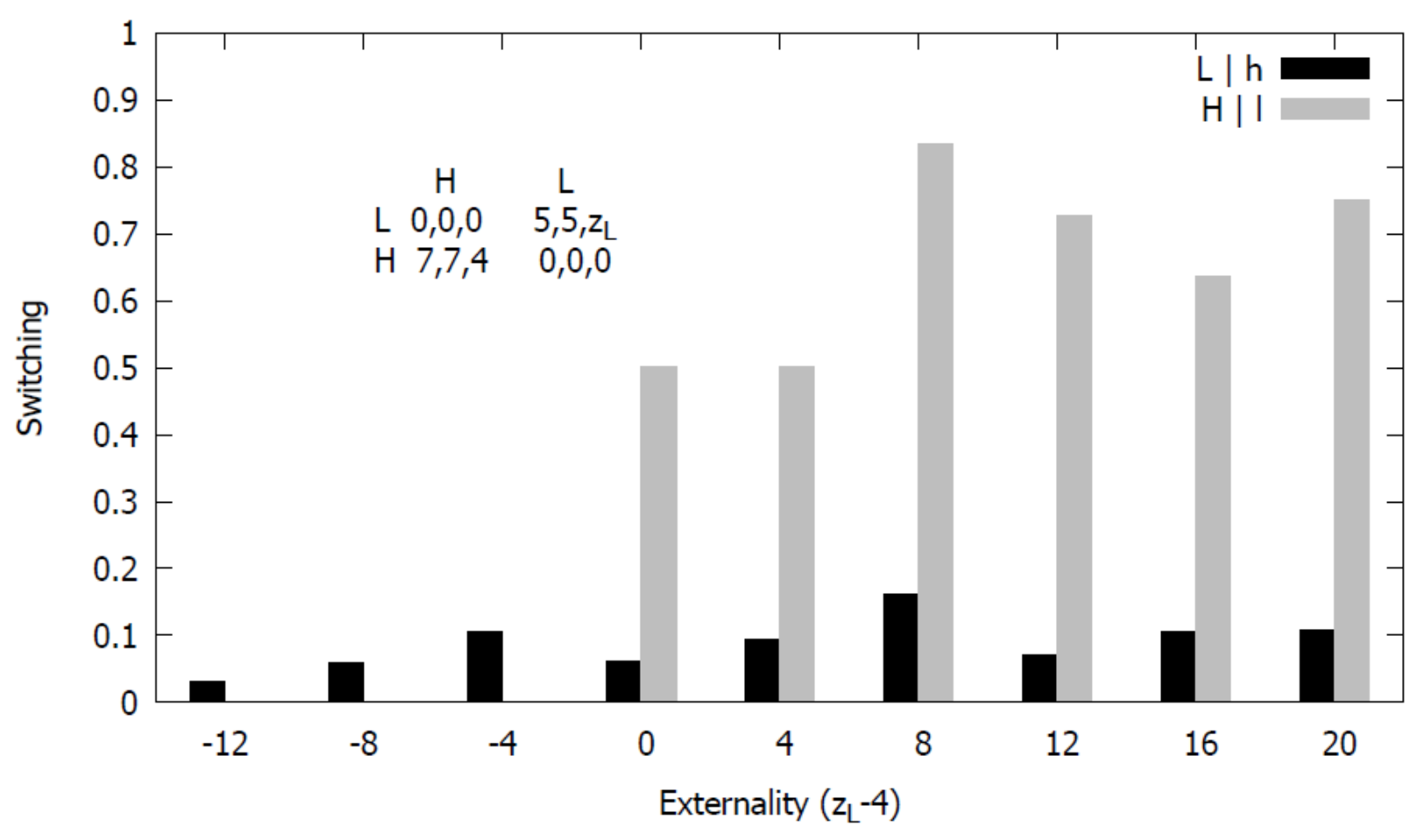


FOR ONLINE PUBLICATION

Supplementary Material for

Tacit Coordination in Games with Third-Party Externalities

By James Bland and Nikos Nikiforakis 
FOR ONLINE PUBLICATION

\begin{tabular}{|c|c|c|c|}
\hline & $(1)$ & $(2)$ & $(3)$ \\
\hline (Absolute) Negative Externality & $\begin{array}{l}-0.0452 \\
(0.0626)\end{array}$ & $\begin{array}{l}-0.0762 \\
(0.0491)\end{array}$ & \\
\hline Positive Externality & $\begin{array}{c}0.0307 \\
(0.0510)\end{array}$ & $\begin{array}{c}0.0190 \\
(0.0238)\end{array}$ & \\
\hline $\mathrm{E}=-12$ (dummy) & & & $\begin{array}{l}-0.642 \\
(0.816)\end{array}$ \\
\hline $\mathrm{E}=-8($ dummy $)$ & & & $\begin{array}{c}0.0000 \\
(0.726)\end{array}$ \\
\hline $\mathrm{E}=-4$ (dummy) & & & $\begin{array}{c}0.656 \\
(0.671)\end{array}$ \\
\hline $\mathrm{E}=4($ dummy $)$ & & & $\begin{array}{c}0.656 \\
(0.671)\end{array}$ \\
\hline $\mathrm{E}=8($ dummy $)$ & & & $\begin{array}{c}1.154 \\
(0.647)\end{array}$ \\
\hline $\mathrm{E}=12$ (dummy) & & & $\begin{array}{c}0.462 \\
(0.685)\end{array}$ \\
\hline $\mathrm{E}=16$ (dummy) & & & $\begin{array}{c}0.999 \\
(0.653)\end{array}$ \\
\hline $\mathrm{E}=20$ (dummy) & & & $\begin{array}{c}0.834 \\
(0.661)\end{array}$ \\
\hline Constant & $\begin{array}{c}-2.533^{* * *} \\
(0.465)\end{array}$ & $\begin{array}{c}-3.051^{* * *} \\
(0.448)\end{array}$ & $\begin{array}{c}-3.640^{* * *} \\
(0.632)\end{array}$ \\
\hline Number of observations & 204 & 612 & 612 \\
\hline Log likelihood & -52.70 & -183.5 & -181.4 \\
\hline Decisions & First 3 & All & All \\
\hline $\operatorname{lnsig} 2 \mathrm{u}$ & -9.750 & $1.127^{* *}$ & $1.159^{* *}$ \\
\hline cons & $(32.79)$ & $(0.390)$ & $(0.389)$ \\
\hline
\end{tabular}

Table S-1 - The impact of third-party externalities on the probability to select action $L$ in Experiment 2 
FOR ONLINE PUBLICATION

\begin{tabular}{|c|c|c|c|c|c|c|}
\hline & $(1)$ & $(2)$ & $(3)$ & $(4)$ & $(5)$ & $(6)$ \\
\hline $\begin{array}{l}\text { (Absolute) Negative } \\
\text { Externality }\end{array}$ & $\begin{array}{c}0.0686 \\
(0.0681)\end{array}$ & $\begin{array}{c}0.0963 \\
(0.0566)\end{array}$ & & $\begin{array}{c}0.0882 \\
(0.0876)\end{array}$ & $\begin{array}{c}0.115 \\
(0.0748)\end{array}$ & \\
\hline Positive Externality & $\begin{array}{l}-0.0686 \\
(0.0681)\end{array}$ & $\begin{array}{l}-0.0493 \\
(0.0327)\end{array}$ & & $\begin{array}{l}-0.0882 \\
(0.0876)\end{array}$ & $\begin{array}{l}-0.0537 \\
(0.0432)\end{array}$ & \\
\hline $\mathrm{E}=-12$ (dummy) & & & $\begin{array}{c}0.824 \\
(0.829)\end{array}$ & & & $\begin{array}{c}1.059 \\
(1.096)\end{array}$ \\
\hline $\mathrm{E}=-8($ dummy $)$ & & & $\begin{array}{c}2.13 \mathrm{e}-13 \\
(0.829)\end{array}$ & & & $\begin{array}{c}-4.55 \mathrm{e}-13 \\
(1.096)\end{array}$ \\
\hline $\mathrm{E}=-4($ dummy $)$ & & & $\begin{array}{l}-0.529 \\
(0.829)\end{array}$ & & & $\begin{array}{l}-0.765 \\
(1.096)\end{array}$ \\
\hline $\mathrm{E}=4$ (dummy) & & & $\begin{array}{l}-1.235 \\
(0.829)\end{array}$ & & & $\begin{array}{l}-1.588 \\
(1.096)\end{array}$ \\
\hline $\mathrm{E}=8$ (dummy) & & & $\begin{array}{l}-1.059 \\
(0.829)\end{array}$ & & & $\begin{array}{l}-0.824 \\
(1.096)\end{array}$ \\
\hline $\mathrm{E}=12$ (dummy) & & & $\begin{array}{l}-0.824 \\
(0.829)\end{array}$ & & & $\begin{array}{l}-1.059 \\
(1.096)\end{array}$ \\
\hline $\mathrm{E}=16$ (dummy) & & & $\begin{array}{l}-1.353 \\
(0.829)\end{array}$ & & & $\begin{array}{l}-1.235 \\
(1.096)\end{array}$ \\
\hline $\mathrm{E}=20$ (dummy) & & & $\begin{array}{l}-1.647^{*} \\
(0.829)\end{array}$ & & & $\begin{array}{l}-2.118 \\
(1.096)\end{array}$ \\
\hline Constant & $\begin{array}{c}11.94^{* * *} \\
(0.600) \\
\end{array}$ & $\begin{array}{c}11.37^{* * *} \\
(0.493) \\
\end{array}$ & $\begin{array}{c}11.94^{* * *} \\
(0.663) \\
\end{array}$ & $\begin{array}{c}15.35^{* * *} \\
(0.772) \\
\end{array}$ & $\begin{array}{c}14.68^{* * *} \\
(0.634) \\
\end{array}$ & $\begin{array}{c}15.35^{* * *} \\
(0.864) \\
\end{array}$ \\
\hline $\begin{array}{l}\text { Number of } \\
\text { observations }\end{array}$ & 204 & 612 & 612 & 204 & 612 & 612 \\
\hline R-squared (overall) & 0.0184 & 0.0154 & 0.0187 & 0.0184 & 0.0120 & 0.0160 \\
\hline Role of player & $\mathrm{X}$ and $\mathrm{Y}$ & $\mathrm{X}$ and $\mathrm{Y}$ & $\mathrm{X}$ and $\mathrm{Y}$ & All & All & All \\
\hline Decisions & First 3 & All & All & First 3 & All & All \\
\hline
\end{tabular}

Table S-2 - The impact of third-party externalities on the earnings of the decision makers and overall efficiency in Experiment 2

(Linear regression with individual-level random effects) 
FOR ONLINE PUBLICATION

\begin{tabular}{lcc}
\hline \hline & Experiment 1 & Experiment 2 \\
\hline (absolute) negative externality & $0.123^{* * *}$ & -0.0781 \\
& $(0.0299)$ & $(0.0520)$ \\
Positive externality & 0.0380 & -0.000849 \\
& $(0.0546)$ & $(0.0256)$ \\
Dummy = 1 for action I in Allocation & $2.395^{* * *}$ & $2.522^{* * *}$ \\
Task with same externality & $(0.525)$ & $(0.586)$ \\
Constant & $1.506^{* * *}$ & $-3.365^{* * *}$ \\
& $(0.386)$ & $(0.506)$ \\
\hline Number of observations & 630 & 612 \\
Log likelihood & -167.6 & -172.5 \\
lnsig2u & $1.506^{* * *}$ & $1.316^{* * *}$ \\
cons & $(0.386)$ & $(0.399)$ \\
\hline \hline Logit with individual-level random effects & \\
Standard errors in parentheses * $<<0.05,{ }^{* *} \mathrm{p}<0.01,{ }^{* * *} \mathrm{p}<0.001$ & \\
Table S-3 - The impact of elicited preferences in the Allocation Task on \\
\multicolumn{2}{c}{ coordination game actions. }
\end{tabular}




\section{FOR ONLINE PUBLICATION}

\section{Experimental Instructions}

Note: Instructions for Players X and Y were identical for all experiments and for all sequences. Instructions for Person $\mathrm{Z}$ contained the same information about their role and the role of $\mathrm{X}$ and $\mathrm{Y}$, but showed payoffs relevant to their experiment. For brevity, we show instructions only for (1) Player X and (2) Person $\mathrm{Z}$ in Experiment 1. The rest of the instructions are available from the authors upon request.

\section{INSTRUCTIONS - Part $1(\mathrm{X})$}

\section{General}

You are now taking part in an economic experiment. The instructions which have been distributed to you are for your private information. Please do not communicate with the other participants during the experiment. Should you have any questions, please raise your hand.

There are no right or wrong answers in the experiment. However, your earnings depend on your decisions and those made by others in the experiment. It is therefore important that you take your time to understand the instructions.

During the experiment we shall not speak of Dollars, but of Experimental Currency Units (ECU). Your entire earnings will be calculated in ECUs. At the end of the experiment the total amount of ECUs you have earned will be converted to Dollars at the rate of $1 \mathrm{ECU}=50$ cents. Your entire earnings will then be paid to you in cash in private. Other participants will not be informed about your earnings. Once you have been paid, you will be able to leave without interacting further with other participants.

Please note that in some situations in this experiment, participants may have negative earnings. Each participant will be given 20 ECUs $(\$ 10)$ at the start of the experiment to compensate for any such losses.

\section{The parts of the experiment}

The experiment consists of two parts. These instructions are for Part 1. You will receive further instructions for Part 2 once Part 1 is completed. Please note that your decisions in Part 1 will in no way affect your earnings (or that of others) in Part 2.

\section{Roles in the experiment}




\section{FOR ONLINE PUBLICATION}

At the start of Part 1, you will be placed in a group with two other individuals. That is, you will be in a group of 3 .

Each individual has a different role in the experiment. The roles are determined by the number you drew when entering the laboratory. You have been assigned the role of Person $X$. The other two individuals in your group have been assigned the role of Person Y and Person Z. Participants will retain their roles until the end of the experiment.

The individual assigned the role of Person $\mathrm{Z}$ does not have a decision to make in Part 1. Person Z's earnings depend on the choices made by Person X (you) and Person Y. Person $\mathrm{Z}$ will be informed of the earnings that $\mathrm{s} /$ he received during Part 1 at the end of the experiment together with the choices that were available to you and the actions that you took in this part.

In particular, the individual assigned the role of Person $\mathrm{Z}$ has been told the following: "Apart from the $20 \mathrm{ECU}$ participation fee, your earnings in this part will depend on the choices made by the individuals assigned the roles of Person X and Person $\mathrm{Y}$ in your group. You will be informed of the options available to Person $\mathrm{X}$ and Person $\mathrm{Y}$ in your group, their choices and also your earnings at the end of the experiment."

\section{Anonymity}

Participants will never be informed about the identity of the other members in their group or the role that others have been assigned. Once the experiment is completed, individuals will receive their payment privately and will be able to leave without further interacting with other participants.

\section{Your task in Part 1}

In this part, individuals assigned the roles of Persons $\mathrm{X}$ and $\mathrm{Y}$ will be presented with 9 different "scenarios." In each scenario, individuals assigned the roles of Persons $\mathrm{X}$ and $\mathrm{Y}$ will have to choose one of two actions.

You (Person X) must choose between actions $x 1$ and $x 2$. Person $\mathrm{Y}$ will have to choose between actions $y 1$ and $y 2$. Earnings in this part will depend on the decisions made by you and the group member assigned the role of Person Y.

An example of the choices that you will have to make is given in Table 1 and illustrates how your choice may affect your earnings (this example will not be used in the experiment). 


\section{FOR ONLINE PUBLICATION}

Table 1

\begin{tabular}{cccc}
\hline & \multicolumn{3}{c}{ Y's actions } \\
\hline & \multicolumn{2}{c}{$\boldsymbol{y} \mathbf{1}$} & $\boldsymbol{y} \mathbf{2}$ \\
\cline { 2 - 4 } X's & $\boldsymbol{x} \mathbf{1}$ & $0,0,0$ & $8,5,6$ \\
actions & $\boldsymbol{x} \mathbf{2}$ & $10,9,7$ & $0,0,0$ \\
\hline
\end{tabular}

For each combination of actions in Table 1 (e.g. x1 and y1), the leftmost digit indicates the earnings (in ECUs) for Person $\mathrm{X}$ (you), the middle digit indicates the earnings for Person $\mathrm{Y}$, and the right digit indicates the earnings for Person $\mathrm{Z}$.

For example, suppose that you (Person $\mathrm{X}$ ) choose action $x 2$. If Person $\mathrm{Y}$ chooses action $y 1$, then you will receive 10 ECUs, Person $\mathrm{Y}$ will receive 9 ECUs, and Person $\mathrm{Z}$ will receive 7 ECUs. Alternatively, if you choose action $x 1$, and Person $\mathrm{Y}$ chooses action $y 1$, all three individuals in your group (including yourself) will receive no earnings.

Note that negative values denote losses, which shall be deducted from an individual's final payment. For example, suppose that you (Person X) have to choose an action based on Table 2 (this example will not be used in the experiment):

Table 2

\begin{tabular}{cccc}
\hline & \multicolumn{3}{c}{ Y's actions } \\
\hline & & $y \mathbf{1}$ & $\boldsymbol{y} \mathbf{2}$ \\
\cline { 2 - 4 } X's & $\boldsymbol{x} \mathbf{1}$ & $0,0,0$ & $-1,5$, \\
actions & $\boldsymbol{x} 2$ & $10,9,7$ & $0,0,0$ \\
\hline
\end{tabular}

Suppose that you choose action $\mathrm{x}$. If Person $\mathrm{Y}$ chooses action y2, you will lose 1 ECU, Person Y will earn 5 ECUs and Person $Z$ will earn 6 ECUs. If you choose action $\mathrm{x} 2$ instead, and Person $\mathrm{Y}$ chooses y1 you will earn 10 ECUs, Person $\mathrm{Y}$ will earn 9 ECUs and Person $\mathrm{Z}$ will earn 7 ECUs.

Earnings in Part 1

As explained, in Part 1 you will make 9 decisions. The outcome from all nine scenarios will be added to your earnings.

Please note that no feedback shall be given between scenarios about the choice of Person X and Y. You should therefore consider these nine scenarios to be nine entirely separate events. Note also that none of the participants will be informed about your earnings from Part 1 until the end of the experiment. This implies 


\section{FOR ONLINE PUBLICATION}

that your decisions in this part will in no way affect your earnings in subsequent parts of the experiment.

Do you have any questions? If you do, please raise your hand to attract the attention of an experimenter. Otherwise, please proceed to answer the questions on the next page.

\section{Control Questions}

Please answer the following questions. Once you have finished answering the questions please raise your hand to attract the attention of an experimenter.

Consider the following table:

\begin{tabular}{cccc}
\hline & \multicolumn{3}{c}{ Y's actions } \\
\hline & \multicolumn{2}{c}{$y \mathbf{1}$} & $\boldsymbol{y} \mathbf{2}$ \\
\cline { 2 - 4 } X's & $\boldsymbol{x} \mathbf{1}$ & $0,0,0$ & $4,5,2$ \\
actions & $\boldsymbol{x} \mathbf{2}$ & $6,-4,10$ & $0,0,0$ \\
\hline
\end{tabular}

1. If Person $\mathrm{X}$ chooses action $x 1$, and Person $\mathrm{Y}$ chooses action $y 1$ :
a. What would be the earnings of person $\mathrm{X}$ ?
ECUs
-----
-----
ECUs
b. What would be the earnings of person Y?
c. What would be the earnings of person Z?
ECUs

2. If Person $\mathrm{X}$ chooses action $x 2$, and Person $\mathrm{Y}$ chooses action $y$ 1:
a. What would be the earnings of person $X$ ?
ECUs
b. What would be the earnings of person Y?
c. What would be the earnings of person $Z$ ?

ECUs
----- ECUs
----- ECUs

3. If Person $\mathrm{X}$ chooses action $x 1$, and Person $\mathrm{Y}$ chooses action $y 2$ :
a. What would be the earnings of person $X$ ?
ECUs
b. What would be the earnings of person Y?
c. What would be the earnings of person $\mathrm{Z}$ ?

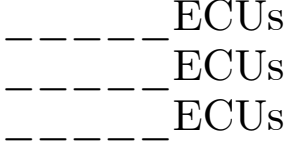

4. How many scenarios will you be presented with?

5. How many scenarios will count towards your payment?

6. True or False: The only ones making decisions in Part 1 are the individuals assigned the roles of Person $\mathrm{X}$ and $\mathrm{Y}$.

$$
\mathrm{T} / \mathrm{F}
$$

7. Will you be informed of the actions taken by other people in your group during Part 1? 


\section{FOR ONLINE PUBLICATION}

8. Will other people in your group know the actions you take during Part 1 ?

$\mathrm{Y} / \mathrm{N}$

9. Will Person Z receive any information about Person X's or Person Y's choices?

10. I have been assigned the role of:

Person X Person Y Person Z

11. For every ECU that I earn, how much will I be paid at the end of the experiment?

$\$$ 


\section{FOR ONLINE PUBLICATION}

\section{INSTRUCTIONS - Part $2(\mathrm{X})$}

These are your instructions for Part 2 of the experiment.

In Part 2, you will be in the same group as in Part 1. Further, each participant will retain the role he or she was assigned at the beginning of Part 1 . Therefore, each group will consist of one Person X, one Person Y and one Person Z.

The individual assigned the role of Person $Z$ does not have a decision to make in Part 2. Person Z's earnings depend on the choices made by Person X (you) and Person Y. Person $\mathrm{Z}$ will be informed of the earnings that $\mathrm{s} /$ he received during Part 2 at the end of the experiment together with the choices that were available to you and the actions that you took in this part.

\section{Your task in Part 2}

In Part 2, you will be presented with 9 "cases." Each case will consist of a different pair of earnings' allocations. Each allocation specifies the earnings of Person X, Y, and Z. Your task in Part 2 will be to select one of the allocations in each case.

Table 3 - Example of task in Part 2

\begin{tabular}{c|ccccccc}
\hline \multirow{3}{*}{ Case } & \multicolumn{3}{|c}{ Allocation A } & & \multicolumn{3}{c}{ Allocation B } \\
& Person & Person & Person & & Person & Person & Person \\
& $\mathrm{X}$ & $\mathrm{Y}$ & $\mathrm{Z}$ & & $\mathrm{X}$ & $\mathrm{Y}$ & $\mathrm{Z}$ \\
\cline { 2 - 5 } \cline { 7 - 9 } & 10 & 10 & 7 & & 8 & 3 & 7 \\
\hline
\end{tabular}

Table 3 provides an example of the task in Part 2. (This example will not be used in the experiment). You are asked to choose between Allocation A and Allocation B. Each allocation will determine the earnings of Person X (you), Person Y and Person Z. If Allocation A is chosen, you will earn 10 ECUs, Person $\mathrm{Y}$ will earn 10 ECUs, and Person $\mathrm{Z}$ will earn 7 ECUs. On the other hand, if Allocation $\mathrm{B}$ is chosen, then you will earn 8 ECUs, Person $\mathrm{Y}$ will earn 3 ECUs, and Person $\mathrm{Z}$ will earn 7 ECUs.

\section{How are my earnings determined in Part 2?}

As explained, in Part 2, you will make 9 decisions. After all participants complete Part 2, the computer will randomly select one of the 9 cases. Each case will be equally likely to be selected. The allocation you chose in the selected case will determine the earnings to be added to the earnings of Persons $\mathrm{X}$ (you), Y and Z 


\section{FOR ONLINE PUBLICATION}

from Part 1. This means that only one of your decisions will determine your earnings from Part 2 and that you should carefully consider each of the decisions you make.

Note that, separately from you, Person Y will also be selecting allocations in Part 2. After the computer randomly selects one of your 9 choices, the computer will randomly select one of the 9 choices made by Person Y. The allocation that Person $\mathrm{Y}$ chose in this case will determine the earnings to be added to the earnings of Person X (you), Y and Z.

\section{Information about earnings}

Participants in the experiment will not be informed about their earnings from Part 2 until the end of the experiment. As in Part 1, Person $\mathrm{Z}$ has been presented with a description of the task, and will know the choices that were available to you and the choices that you made in the experiment.

Do you have any questions? If you do, please raise your hand to attract the attention of an experimenter. Otherwise, please proceed to answer the questions below.

\section{Control Questions}

Please answer the following questions. Once you have finished answering the questions please raise your hand to attract the attention of an experimenter.

Consider the following table:

\begin{tabular}{c|ccccccc}
\hline \multirow{2}{*}{ Case } & \multicolumn{3}{|c}{ Allocation A } & & \multicolumn{3}{c}{ Allocation B } \\
& Person & Person & Person & & Person & Person & Person \\
& $\mathrm{X}$ & $\mathrm{Y}$ & $\mathrm{Z}$ & & $\mathrm{X}$ & $\mathrm{Y}$ & $\mathrm{Z}$ \\
\cline { 2 - 5 } & 10 & -1 & 7 & & 8 & 3 & 7 \\
\hline
\end{tabular}

1. If you selected allocation A:

a. What are Person X's earnings?

ECUs

b. What are Person Y's earnings?

ECUs

c. What are Person Z's earnings?

ECUs

2. If you selected allocation B:

a. What are Person X's earnings?

ECUs

b. What are Person Y's earnings?

ECUs 


\section{FOR ONLINE PUBLICATION}

c. What are Person Z's earnings?

ECUs

3. How many cases will be presented in Part 2?

4. How many of your decisions in this part will count towards your payment?

5. Can your choices in Part 2 affect other people's decisions in the experiment? $\mathrm{Y} / \mathrm{N}$

6. When will you (and the other participants) be informed about the earnings from Part 2?

a. After each case

b. At the end of the experiment 


\section{FOR ONLINE PUBLICATION}

\section{INSTRUCTIONS - Part $1(\mathrm{Z})$}

\section{General}

You are now taking part in an economic experiment. The instructions which have been distributed to you are for your private information. Please do not communicate with the other participants during the experiment. Should you have any questions, please raise your hand.

During the experiment we shall not speak of Dollars, but of Experimental Currency Units (ECU). Your entire earnings will be calculated in ECUs. At the end of the experiment the total amount of ECUs you have earned will be converted to Dollars at the rate of $1 \mathrm{ECU}=50$ cents. Your entire earnings will then be paid to you in cash in private. Other participants will not be informed about your earnings. Once you have been paid, you will be able to leave without interacting further with other participants.

Please note that in some situations in this experiment, participants may have negative earnings. Each participant will be given 20 ECUs $(\$ 10)$ at the start of the experiment to compensate for any such losses.

\section{The parts of the experiment}

The experiment consists of two parts. These instructions are for Part 1. You will receive further instructions for Part 2 once Part 1 is completed.

\section{Roles in the experiment}

At the start of Part 1, you will be placed in a group with two other individuals. That is, you will be in a group of 3 .

Each individual has a different role in the experiment. The roles are determined by the number you drew when entering the laboratory. You have been assigned the role of Person $Z$. The other two individuals in your group have been assigned the role of Person X and Person Y. Participants will retain their roles until the end of the experiment.

Individuals assigned the role of Person $\mathrm{Z}$ do not have a decision to make in this part. Apart from the 20 ECU participation fee, your earnings in this part will depend on the choices made by the individuals assigned the roles of Person $\mathrm{X}$ and Person Y in your group. You will be informed of the options available to Person 


\section{FOR ONLINE PUBLICATION}

$\mathrm{X}$ and Person $\mathrm{Y}$ in your group, their choices and also your earnings at the end of the experiment.

\section{Anonymity}

Participants will never be informed about the identity of the other members in their group or the role that others have been assigned. Once the experiment is completed, individuals will receive their payment privately and will be able to leave without further interacting with other participants.

\section{Your task in Part 1}

You do not have a decision to make in this part. Your earnings in this part will depend on the choices made by the individuals assigned the roles of Person $\mathrm{X}$ and Person $\mathrm{Y}$ in your group. Presented below is an explanation of the task Person $\mathrm{X}$ and $\mathrm{Y}$ are performing which shall determine your earnings.

\section{Person $\mathrm{X}$ and Person Y's task in Part 1}

In this part, individuals assigned the roles of Persons $\mathrm{X}$ and $\mathrm{Y}$ will be presented with 9 different "scenarios." In each scenario, individuals assigned the roles of Persons $\mathrm{X}$ and $\mathrm{Y}$ will have to choose one of two actions.

Person $\mathrm{X}$ must choose between actions $\mathrm{x} 1$ and $\mathrm{x} 2$. Person $\mathrm{Y}$ will have to choose between actions $y 1$ and $y 2$. Earnings in this part will depend on the decisions made by Persons $\mathrm{X}$ and $\mathrm{Y}$.

An example of the choices that they will have to make is given in Table 1 and illustrates how their choice may affect your earnings (this example will not be used in the experiment).

Table 1

\begin{tabular}{|c|c|c|c|}
\hline & & \multicolumn{2}{|c|}{ Y's actions } \\
\hline & & $y 1$ & $y^{2}$ \\
\hline $\begin{array}{c}\text { X's } \\
\text { actions }\end{array}$ & $\begin{array}{l}x 1 \\
x 2\end{array}$ & $\begin{array}{c}0,0,0 \\
10,9,7\end{array}$ & $\begin{array}{l}8,5,6 \\
0,0,0\end{array}$ \\
\hline
\end{tabular}

For each combination of actions in Table 1 (e.g. x1 and y1), the leftmost digit indicates the earnings (in ECUs) for Person $\mathrm{X}$, the middle digit indicates the 


\section{FOR ONLINE PUBLICATION}

earnings for Person Y, and the right digit indicates the earnings for Person Z (you).

For example, suppose that Person $\mathrm{X}$ chooses action $\mathrm{x}$ 2. If Person $\mathrm{Y}$ chooses action $y 1$, then Person $\mathrm{X}$ will receive 10 ECUs, Person $\mathrm{Y}$ will receive 9 ECUs, and you will receive 7 ECUs. Alternatively, if Person $\mathrm{X}$ chooses action $x 1$, and Person $\mathrm{Y}$ chooses action $y 1$, all three individuals in your group (including yourself) will receive no earnings.

Note that negative values denote losses, which shall be deducted from an individual's final payment. For example, suppose that Persons $\mathrm{X}$ and $\mathrm{Y}$ have to choose an action based on Table 2 (this example will not be used in the experiment):

Table 2

\begin{tabular}{cccc}
\hline & \multicolumn{3}{c}{ Y's actions } \\
\hline & & $y \mathbf{1}$ & $\boldsymbol{y} \mathbf{2}$ \\
\cline { 2 - 4 } X's & $\boldsymbol{x} \mathbf{1}$ & $0,0,0$ & $-1,5,6$ \\
actions & $\boldsymbol{x} \mathbf{2}$ & $10,9,7$ & $0,0,0$
\end{tabular}

Suppose that Person $\mathrm{X}$ chooses action $x$ 1. If Person $\mathrm{Y}$ chooses action $y 2$, Person $\mathrm{X}$ will lose 1 ECU, Person $\mathrm{Y}$ will earn 5 ECUs and you will earn 6 ECUs. If Person $\mathrm{X}$ chooses action $x 2$ instead, and Person $\mathrm{Y}$ chooses $y 1$ Person $\mathrm{X}$ will earn 10 ECUs, Person $\mathrm{Y}$ will earn 9 ECUs and you will earn 7 ECUs.

\section{How are my earnings determined in Part 1}

As explained, in Part 1 Persons $\mathrm{X}$ and $\mathrm{Y}$ will make 9 decisions. The outcome from all five scenarios will be added to your earnings. You will be informed of the choices made by Persons $\mathrm{X}$ and $\mathrm{Y}$ at the end of the experiment.

\section{The scenarios in Part 1}

The nine scenarios that Persons $\mathrm{X}$ and $\mathrm{Y}$ will be shown in this part are presented below: 


\section{FOR ONLINE PUBLICATION}

\begin{tabular}{cccc}
\hline & \multicolumn{3}{c}{ Y's actions } \\
\hline & & $y \mathbf{1}$ & $\boldsymbol{y} \mathbf{2}$ \\
\cline { 2 - 4 } X's & $\boldsymbol{x} \mathbf{1}$ & $0,0,0$ & $5,5,4$ \\
actions & $\boldsymbol{x} \mathbf{2}$ & $7,7,-16$ & $0,0,0$ \\
\hline
\end{tabular}

\begin{tabular}{cccc}
\hline & \multicolumn{3}{c}{ Y's actions } \\
\hline & & $y \mathbf{1}$ & $\boldsymbol{y} \mathbf{2}$ \\
\cline { 2 - 4 } X's & $\boldsymbol{x} \mathbf{1}$ & $0,0,0$ & $5,5,4$ \\
actions & $\boldsymbol{x} \mathbf{2}$ & $7,7,16$ & $0,0,0$ \\
\hline
\end{tabular}

\begin{tabular}{cccc}
\hline & \multicolumn{3}{c}{ Y's actions } \\
\hline & & $y 1$ & $y 2$ \\
X's & $\boldsymbol{x} \mathbf{1}$ & $0,0,0$ & $5,5,4$ \\
actions & $\boldsymbol{x} \mathbf{2}$ & $7,7,-12$ & $0,0,0$ \\
\hline
\end{tabular}

\begin{tabular}{cccc}
\hline & \multicolumn{3}{c}{ Y's actions } \\
\hline & & $y \mathbf{1}$ & $\boldsymbol{y} \mathbf{2}$ \\
\cline { 2 - 4 } X's & $\boldsymbol{x} \mathbf{1}$ & $0,0,0$ & $5,5,4$ \\
actions & $\boldsymbol{x} \mathbf{2}$ & $7,7,-8$ & $0,0,0$ \\
\hline
\end{tabular}

\begin{tabular}{cccc}
\hline & \multicolumn{3}{c}{ Y's actions } \\
\hline & & $y \mathbf{1}$ & $\boldsymbol{y} \mathbf{2}$ \\
\cline { 2 - 4 } X's & $\boldsymbol{x} \mathbf{1}$ & $0,0,0$ & $5,5,4$ \\
actions & $\boldsymbol{x} \mathbf{2}$ & $7,7,-4$ & $0,0,0$ \\
\hline
\end{tabular}

\begin{tabular}{cccc}
\hline & & \multicolumn{2}{c}{ Y's actions } \\
\hline & & $y \mathbf{1}$ & $\boldsymbol{y} \mathbf{2}$ \\
\cline { 2 - 4 } X's & $\boldsymbol{x} \mathbf{1}$ & $0,0,0$ & $5,5,4$ \\
actions & $\boldsymbol{x} \mathbf{2}$ & $7,7,0$ & $0,0,0$ \\
\hline
\end{tabular}

\begin{tabular}{cccc}
\hline & \multicolumn{3}{c}{ Y's actions } \\
\hline & & $y \mathbf{1}$ & $\boldsymbol{y} \mathbf{2}$ \\
\cline { 2 - 4 } X's & $\boldsymbol{x} \mathbf{1}$ & $0,0,0$ & $5,5,4$ \\
actions & $\boldsymbol{x} \mathbf{2}$ & $7,7,4$ & $0,0,0$ \\
\hline
\end{tabular}

Y's actions

\begin{tabular}{cccc}
\hline & & $y \mathbf{1}$ & $\boldsymbol{y} \mathbf{2}$ \\
\cline { 2 - 4 } X's & $\boldsymbol{x} \mathbf{1}$ & $0,0,0$ & $5,5,4$ \\
actions & $\boldsymbol{x} \mathbf{2}$ & $7,7,8$ & $0,0,0$ \\
\hline
\end{tabular}

\begin{tabular}{cccc}
\hline & \multicolumn{3}{c}{ Y's actions } \\
\hline & & $y \mathbf{1}$ & $\boldsymbol{y} \mathbf{2}$ \\
\cline { 2 - 4 } X's & $\boldsymbol{x} \mathbf{1}$ & $0,0,0$ & $5,5,4$ \\
actions & $\boldsymbol{x} \mathbf{2}$ & $7,7,12$ & $0,0,0$ \\
\hline
\end{tabular}




\section{FOR ONLINE PUBLICATION}

If you have any questions, please raise your hand to attract the attention of an experimenter.

If you have something to read, you are welcome to do so.

The experimenters have some newspapers and magazines available. If you would like one of these to read, please raise your hand to attract the attention of an experimenter.

\section{INSTRUCTIONS - Part $2(\mathrm{Z})$}

These are your instructions for Part 2 of the experiment.

In Part 2, you will be in the same group as in Part 1. Further, each participant will retain the role he or she was assigned at the beginning of Part 1 . Therefore, each group will consist of one Person X, one Person Y and one Person Z.

\section{Your task in Part 2}

You do not have a decision to make in this part. Your earnings in this part will depend on the choices made by the individuals assigned the roles of Person $\mathrm{X}$ and Person $\mathrm{Y}$ in your group, and an element of luck. Presented below is an explanation of the task Person $\mathrm{X}$ and $\mathrm{Y}$ are performing which shall determine your earnings.

\section{Person X and Person Y's task in Part 2}

In Part 2, Persons $\mathrm{X}$ and $\mathrm{Y}$ will be presented with 9 "cases." Each case will consist of a different pair of earnings' allocations. Each allocation specifies the earnings of Person X, Y, and Z. Their task in Part 2 will be to select one of the allocations in each case.

Table 3 - Example of task in Part 2

\begin{tabular}{c|ccccccc}
\hline \multirow{3}{*}{ Case } & \multicolumn{3}{|c}{ Allocation A } & & \multicolumn{3}{c}{ Allocation B } \\
& Person & Person & Person & & Person & Person & Person \\
& $\mathrm{X}$ & $\mathrm{Y}$ & $\mathrm{Z}$ & & $\mathrm{X}$ & $\mathrm{Y}$ & $\mathrm{Z}$ \\
\cline { 2 - 6 } \cline { 6 - 8 } & 10 & 10 & 7 & & 8 & 3 & 7 \\
\hline
\end{tabular}

Table 3 provides an example of the task in Part 2. (This example will not be used in the experiment). They are asked to choose between Allocation A and 


\section{FOR ONLINE PUBLICATION}

Allocation B. Each allocation will determine the earnings of Person X, Person Y and Person Z (you). If allocation A is chosen, Person X will earn 10 ECUs, Person $\mathrm{Y}$ will earn 10 ECUs, and you will earn 7 ECUs. On the other hand, if allocation $\mathrm{B}$ is chosen, then Person $\mathrm{X}$ will earn 8 ECUs, Person $\mathrm{Y}$ will earn 3 ECUs, and you will earn 7 ECUs.

\section{How are my earnings determined in Part 2?}

As explained, in Part 2 Persons $\mathrm{X}$ and $\mathrm{Y}$ will each make 9 decisions. After all participants complete Part 2, the computer will randomly select one of the 9 cases. Each case will be equally likely to be selected. The allocation Person $\mathrm{X}$ chose in this case will be added to the earnings of Person $\mathrm{X}, \mathrm{Y}$ and $\mathrm{Z}$ (you). Subsequently, the computer will again randomly select one of the nine cases. The allocation that Person $\mathrm{Y}$ chose in this case will be added to earnings of Person $\mathrm{X}$, $\mathrm{Y}$ and $\mathrm{Z}$ (you).

You will be informed of the choices made by Persons $\mathrm{X}$ and $\mathrm{Y}$ at the end of the experiment. 


\section{FOR ONLINE PUBLICATION}

The cases in Part 2

The nine cases that Persons $\mathrm{X}$ and $\mathrm{Y}$ will be shown in this part are presented below:

\begin{tabular}{l|lllllll}
\hline \multirow{3}{*}{ Case } & \multicolumn{3}{|c}{ Allocation A } & \multicolumn{3}{c}{ ation B } \\
& Person & Person & Person & & Person & Person & Person \\
& $\mathrm{X}$ & $\mathrm{Y}$ & $\mathrm{Z}$ & & $\mathrm{X}$ & $\mathrm{Y}$ & $\mathrm{Z}$ \\
\cline { 2 - 4 } \cline { 5 - 7 } 2 & 7 & 7 & -16 & & 5 & 5 & 4 \\
3 & 7 & 7 & -12 & & 5 & 5 & 4 \\
4 & 7 & 7 & -8 & 5 & 5 & 4 \\
5 & 7 & 7 & -4 & 5 & 5 & 4 \\
6 & 7 & 7 & 0 & 5 & 5 & 4 \\
7 & 7 & 7 & 4 & 5 & 5 & 4 \\
8 & 7 & 7 & 8 & 5 & 5 & 4 \\
9 & 7 & 7 & 12 & 5 & 5 & 4 \\
\hline
\end{tabular}

If you have any questions, please raise your hand to attract the attention of an experimenter.

If you have something to read, you are welcome to do so.

The experimenters have some newspapers and magazines available. If you would like one of these to read, please raise your hand to attract the attention of an experimenter. 